\title{
CFD Study of Industrial FCC Risers: The Effect of Outlet Configurations on Hydrodynamics and Reactions
}

\author{
Gabriela C. Lopes, ${ }^{1}$ Leonardo M. Rosa, ${ }^{1}$ Milton Mori, ${ }^{1}$ \\ José R. Nunhez, ${ }^{1}$ and Waldir P. Martignoni ${ }^{2}$ \\ ${ }^{1}$ School of Chemical Engineering, University of Campinas, 500 Albert Einstein Avenue, 13083-970 Campinas, SP, Brazil \\ ${ }^{2}$ PETROBRAS, 65 República do Chile Avenue, 20031-912 Rio de Janeiro, RJ, Brazil
}

Correspondence should be addressed to Milton Mori, mori@feq.unicamp.br

Received 4 September 2012; Accepted 7 November 2012

Academic Editor: Jerzy Bałdyga

Copyright ( 2012 Gabriela C. Lopes et al. This is an open access article distributed under the Creative Commons Attribution License, which permits unrestricted use, distribution, and reproduction in any medium, provided the original work is properly cited.

Fluid catalytic cracking (FCC) riser reactors have complex hydrodynamics, which depend not only on operating conditions, feedstock quality, and catalyst particles characteristics, but also on the geometric configurations of the reactor. This paper presents a numerical study of the influence of different riser outlet designs on the dynamic of the flow and reactor efficiency. A threedimensional, three-phase flow model and a four-lump kinetic scheme were used to predict the performance of the reactor. The phenomenon of vaporization of the liquid oil droplets was also analyzed. Results showed that small changes in the outlet configuration had a significant effect on the flow patterns and consequently, on the reaction yields.

\section{Introduction}

Although commercially established for over half a century, the fluid catalytic cracking (FCC) process is still widely studied nowadays. Since it is a very profitable operation, any improvement in it can result in large savings for the refinery. In the FCC process, preheated high-boiling liquid oil is injected into the riser reactor, where it is vaporized and cracked into smaller molecules by contact and mixing with the very hot catalyst particles coming from the regenerator. These phenomena cause a gas expansion, which drags the catalyst to the top of the reactor. Since catalytic cracking reactions can only occur after the vaporization of liquid feedstock, mixing of hydrocarbon droplets with catalyst must take place in the riser as soon as possible.

It is known that riser reactors have complex hydrodynamics. They present a high solids concentration near the walls and are also axially divided into dense and dilute regions. In addition, different riser configurations such as the inlet and outlet structures can have a profound effect on the flow patterns mentioned above.

The influence of riser exit geometry on the hydrodynamics of gas-solid circulating fluidized beds (CFB) has been in- vestigated in many studies [1-6]. Although the results reported in these studies apparently conflict quantitatively concerning the influence of riser exit, some common aspects can be observed: (1) the design of the exit has a large effect upon the reflux of solids; (2) abrupt exits cause an increase in the solids holdup and a large backmixing at the top of the riser; (3) increasing the refluxing effect of the exit has proved to increase the mean particle residence time; (4) larger and denser clusters are formed at the walls in the risers with abrupt exits.

In an experimental work, Lim et al. [7] investigated a cold model of a circulating fluidized bed, in a riser with an horizontal and flat cover at the top. They limited the operating conditions, that resulted in stable operation of the circulating fluidized bed, and proposed a model to estimate the ratio of solids that exit the riser to solids that recirculate back into the riser. This model predicts the cases in which solids inertia dominates, and the cases when solids have insufficient inertia to resist the change in airflow.

The presence of reverse core-annulus profile under certain conditions in gas-solid CFBs was also observed in an experimental study by Chew et al. [8]. Although some previous works explain this behavior as a consequence of the 
impact of gas-phase turbulence associated with dilute flows, Chew et al. [8] suggest a dominant factor for reverse coreannulus flow: the particle Stokes number (St). According to their work, particles with large St are more likely to follow more diffuse trajectories after collision rather than following fluid streamlines, because of greater particle inertia relative to fluid viscous forces.

Van Der Meer et al. [3] defined a parameter to quantify the reflux of solids in a square cross-section riser of a laboratory CFB. They concluded that the values of this parameter obtained for the different outlet configurations vary in a factor of 25 , showing that the exit design has a significant effect on riser flow regime.

Pugsley et al. [9] performed experiments with sand and FCC catalyst in two cold CFBs of $0.1 \mathrm{~m}$ and $0.2 \mathrm{~m}$ diameter in order to observe the relative influence of smooth and abrupt exit configurations on the axial pressure drop profile. They concluded that the reflux along the riser length induced by abrupt riser exits is related to the riser diameter and the particle terminal velocity. For heavier and largest particles, the influence of abrupt exits was observed to affect a longer section of the riser when compared to the effect of smaller particles. They also observed that these effects are less pronounced for smaller riser diameters.

In a recent study, Van Engelandt et al. [10] analyzed experimentally and computationally the riser outlet effects induced by an L-outlet and by abrupt T-outlets with different extension heights, outlet surface areas, and gas flow rates. They also observed that the T-outlet configuration is found to induce recirculation by vortex formation in the extension part of the riser and cause a main reflux at the wall opposite to the riser outlet. Moreover, a reduction of the outlet surface area of a T-outlet results in an increased solids holdup in the extension part of the riser. With the increase of the gas flow rate, the position of the vortex and the anisotropy of the fluctuating particle velocities are strongly affected.

A numerical study about the effects of different outlet surface area on the flow pattern was also performed by De Wilde et al. [11]. The results obtained in their simulations showed the need of performing $3 \mathrm{D}$ calculations in order to predict accurately the exit effects of abrupt outlet configurations. Chalermsinsuwan et al. [12] studied different designs of the riser geometries based on the improvement of main factors that have an effect on combustion, gasification, and cracking reaction characteristics, using a 2D transient Eulerian approach.

Das et al. [13] used CFD simulations to investigate the effect of different flow and design parameters on the adsorption reactions in a $\mathrm{SO}_{2}-\mathrm{NO}_{x}$ riser. They showed that the solids recirculation at the top section of the riser, induced by abrupt T outlets significantly, decreases the $\mathrm{NO}$ and $\mathrm{NO}_{2}$ removal, worsening the reactor efficiency. They emphasized that this analysis is just possible due to the use of 3D models, which allows predicting the effects of outlet geometries on the flow and reaction fields.

These works indicate that the hydrodynamics of CFB risers is extremely complex, showing that the distribution of axial solids concentration depends not only on operating conditions such as gas velocity, solids flux, and particle properties, but also on the geometric configuration of the riser. However, despite the considerable number of published studies on the influence of riser exit geometry on the hydrodynamics in gas-solid circulating fluidized beds, very few have addressed the importance of the riser geometry on the FCC reactor performance.

Due to the complexity of the flow and extreme operating conditions, experimental studies of industrial FCC process are rarely found. In this context, computational fluid dynamic (CFD) tools have been used as a way to better understand these phenomena and look for alternatives to improve the reactor performance.

Despite the complex hydrodynamics present in these reactors, most numerical studies in FCC risers that take into account cracking reactions and related phenomena simplify some important fluid dynamics aspects, like considering that the riser follows a plug flow model [14-18] or applying empirical radial dispersion models to consider the coreannulus patterns [19-21].

Through the simulation of FCC process using three different models (plug flow, one-dimensional, and twodimensional dispersion models), Deng et al. [21] showed that the consideration of radial nonuniformity is necessary since it provides a better approximation, reflecting in better results for conversions and yields when compared with experimental plant data. Afterward, Lopes et al. [22] simulated an industrial riser using 3D models and showed that the flow presents nonuniformities and asymmetric patterns which are dependent upon feed flow rates. They also observed that these dynamic characteristics of the flow influence the yields of the cracking reactions. Based on this, the use of simplified models can fail to accurately predict the flow in industrial risers.

Another common simplification applied in numerical studies of FCC processes is related to the instantaneous vaporization of the feedstock, which can result in an incorrect representation of the reactor performance. This assumption is justified in many studies (e.g., [14, 23]) by the rapid vaporization of feed. However, Theologos et al. [24], Gupta and Rao [25], and Lopes et al. [26] presented significant differences in product yields when the feedstock vaporization was modeled using instantaneous or rate vaporization models.

In the present work, different designs of the riser exit are studied using CFD techniques. Sophisticated models which take into account vaporization of the liquid droplets, heterogeneous cracking reactions, and catalyst deactivation are applied to the model in order to simulate the reactive flow in industrial scale FCC riser reactors. A parametric study of the hydrodynamic behaviors induced by use of different exit configurations and their effects on the reactions yields is performed. The results obtained are then used to develop a criterion for specifying the riser exit geometries which can improve the reactor efficiency.

\section{Mathematical Model}

The three-phase model used in this work considers a threedimensional gas-liquid-solid flow including heat transfer, 


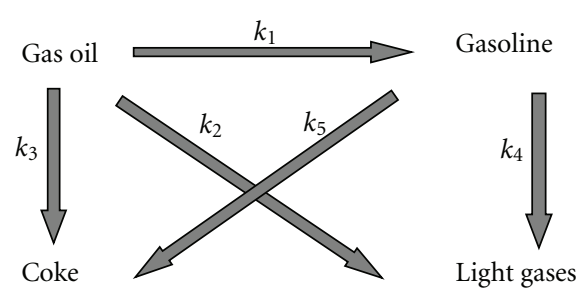

FIGURE 1: Kinetic scheme of the four-lump reaction model.

droplets vaporization, and chemical reactions. This model uses an Eulerian description of the gas and solid phases, while the Lagrangian approach was chosen to describe the liquid droplets. This phase consists of droplets represented as spherical particles and dispersed in the continuous phase. Details of these models are shown below.

2.1. Eulerian Gas-Solid Model. In the Eulerian approach both gas and solid phases are modeled as continuous phases. The characteristics of these phases are then determined by solving the mass, momentum, and energy transport equations and applying closure equations to predict the interaction between the phases.

Since the turbulence in the gas phase was modeled using the Reynolds Stress Model (RSM), one transport equation for each of the Reynolds stress tensor components should be solved. As being an anisotropic model, the RSM is able to predict the flow characteristics in regions where sudden changes in flow directions are expected.

The momentum transfer was modeled using the Gidaspow drag model, which combines the Wen Yu correlation with the Ergun equation. The heat transfer was predicted using the Ranz-Marshall correlation for the Nusselt number. Fluctuations in particle velocity were modeled using the Kinetic Theory of Granular Flow. This theory applies the concept of granular temperature, a quantity related to the kinetic energy due to particle movement, to provide closure terms for the solid-phase stress terms. An algebraic formulation, which assumes that the generation and dissipation of the granular temperature are in equilibrium, was applied to estimate this quantity.

A summary of the governing and constitutive equations can be seen in Table 1 .

2.1.1. Catalytic Cracking Kinetic Model. Many complex reactions occur simultaneously inside the reactor during the FCC process. In order to simplify this kinetic net, a technique widely used is to describe the complex mixtures of hydrocarbons as a reduced number of component groups or lumps. This produces a small number of representative pseudocomponents reacting with each other. This work used a four-lump model proposed by lee et al. [29], in which species with similar properties are grouped into four different lumps: gas oil, gasoline, light gases, and coke. Each lump was defined according to the number of carbons in the molecules as presented in Table 2. The representative reactions of this kinetic scheme are shown in Figure 1.
The general rate equation for reaction $r$ is given by

$$
R_{i, r}=k_{r} C_{i}^{2} \phi
$$

The dependence of kinetic constants on temperature is given by the Arrhenius equation:

$$
k_{r}=k_{r}^{0} \exp \left(-\frac{E_{r}}{R T}\right) .
$$

The parameter $\phi$, appearing in (1), is the catalyst activity function which is related to the deposition of coke on the catalyst surface. It is expressed by

$$
\phi=\exp \left(-K_{c} q_{1}\right),
$$

where $K_{c}$ is the activity constant estimated by Farag et al. [27] as a function of the catalyst type. The value obtained for FCC10 catalyst (sample free of metal traps, nickel, and vanadium) was used in this study. The specific coke concentration, $q_{1}$, is given by

$$
q_{1}=\frac{C_{\text {coke }}}{\rho_{s} \varepsilon_{s}} .
$$

For simplification, it is assumed that coke is not physically deposited on the catalyst surface.

The net source of chemical species $i$ due to reaction (see equation $(G)$ in (Table 1)) is estimated as a sum of the Arrhenius reaction sources over the $N_{r}$ reactions that the species participate in:

$$
\hat{R}_{i}=M_{w, i} \sum_{r=1}^{N_{r}}\left(v_{i} R_{i, r}\right),
$$

where $v_{i}$ is the stoichiometric coefficient of the species $i$, which is positive for products and negative for reagents.

The values used for the kinetic constants were those obtained by Farag et al. [27] for FCC10 catalyst at the temperature of $823 \mathrm{~K}$. Farag et al. [27] concluded that the overcracking of the gasoline formed was negligible because the kinetic constant values for the cracking of the gasoline obtained in their study were very close to zero. Since they do not estimate the activation energies and the heats of reaction, the values reported by Juárez et al. [30] and Han and Chung [16] were adopted. These values are listed in Table 3.

The kinetic constants, given in Table 3, were evaluated at $823 \mathrm{~K}$ and are dependent on the amount of solids. In order to predict these values at any temperature and catalyst concentration, the preexponential factor was isolated from (2), applied for this temperature, and multiplied by the local concentration of solids. Then the kinetic constants were evaluated as follows:

$$
k_{r}\left(T, \varepsilon_{s}\right)=k_{r, 823 \mathrm{~K}}\left(\rho_{s} \mathcal{E}_{s}\right) \exp \left[-\frac{E_{r}}{R}\left(\frac{1}{T}-\frac{1}{823 \mathrm{~K}}\right)\right] .
$$

2.2. Lagrangian Discrete Phase Model. Heavy oil is injected into the reactor as liquid droplets, which are modeled in this work using a Lagrangian discrete phase model. The Lagrangian approach gives more accurate results than the 
TABLE 1: Summary of governing and constitutive equations for Eulerian approach.

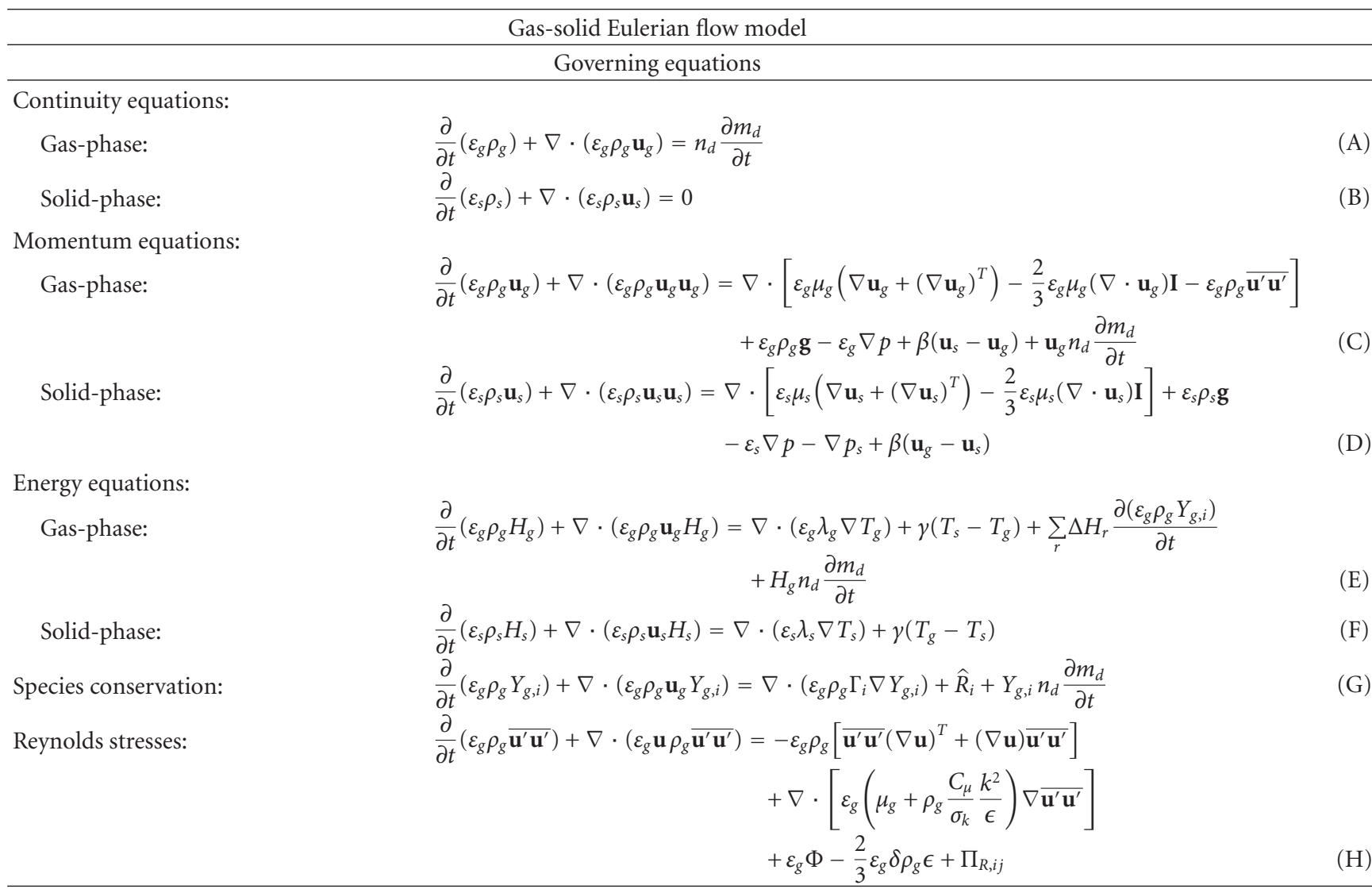

Constitutive equations

Gas-solid momentum exchange

(Gidaspow drag model):

when $\varepsilon_{s}>0.2$,

$\beta=150 \frac{\varepsilon_{s}^{2} \mu_{g}}{\varepsilon_{g} d_{s}^{2}}+\frac{7}{4} \frac{\left|\mathbf{u}_{s}-\mathbf{u}_{g}\right| \varepsilon_{s} \rho_{g}}{d_{s}}$

when $\varepsilon_{s} \leq 0.2$,

$\beta=\frac{3}{4} C_{D} \frac{\left|\mathbf{u}_{s}-\mathbf{u}_{g}\right| \varepsilon_{s} \rho_{g}}{d_{s}} \varepsilon_{s}^{-2.65}$

for $\operatorname{Re}>1000$,

$C_{D}=0.44$

for $\operatorname{Re}<1000$,

$C_{D}=\frac{24}{\operatorname{Re}}\left(1+0.15 \mathrm{Re}^{0.687}\right)$

Gas-solid heat exchange:

$\gamma=\frac{\left(2+0.6 \operatorname{Re}^{0.5} \operatorname{Pr}^{0.3}\right) 6 \lambda \varepsilon_{s} \varepsilon_{g}}{d_{s}^{2}}$

Kinetic theory of granular flow:

Solids pressure:

$p_{s}=\varepsilon_{s} \rho_{s} \Theta_{s}+2 \rho_{s}\left(1+e_{s s}\right) \varepsilon_{s}^{2} g_{0, s s} \Theta_{s}$

Radial distribution:

$g_{0, s s}=\left[1-\left(\frac{\varepsilon_{s}}{\varepsilon_{s, \max }}\right)^{1 / 3}\right]^{-1}$

Granular temperature:

$\Theta_{s}=\left\{\frac{-K_{1} \varepsilon_{s} \nabla \cdot \mathbf{u}_{s}+\sqrt{\left(K_{1} \varepsilon_{s} \nabla \cdot \mathbf{u}_{s}\right)^{2}+4 K_{4} \varepsilon_{s}\left[K_{2}\left(\nabla \cdot \mathbf{u}_{s}\right)^{2}+2 K_{3}\left(\nabla \cdot \mathbf{u}_{s}^{2}\right)\right]}}{2 \varepsilon_{s} K_{4}}\right\}^{2}$

where,

$$
\begin{aligned}
& K_{1}=2\left(1+e_{s s}\right) \rho_{s} g_{0, s s} \\
& K_{2}=\frac{4 d_{s} \rho_{s}\left(1-e_{s s}\right) \varepsilon_{s} g_{0, s s}}{3 \sqrt{\pi}}-\frac{2}{3} K_{3} \\
& K_{3}=\frac{d_{s} \rho_{s}}{2}\left\{\frac{\sqrt{\pi}}{3\left(3-e_{s s}\right)}\left[1+0.4\left(1-e_{s s}\right)\left(3 e_{s s}-1\right) \varepsilon_{s} g_{0, s s}\right]+\frac{8 \varepsilon_{s} g_{0, s s}\left(1+e_{s s}\right)}{5 \sqrt{\pi}}\right\} \\
& K_{4}=\frac{12\left(1-e_{s s}^{2}\right) \rho_{s} g_{0, s s}}{d_{s} \sqrt{\pi}}
\end{aligned}
$$


TABLE 2: Definition of lumps [27].

\begin{tabular}{lc}
\hline Lump & Number of carbons \\
\hline Gas oil & $\mathrm{C}_{13}$ and higher \\
Gasoline & $\mathrm{C}_{5}-\mathrm{C}_{12}$ \\
Light gases & $\mathrm{C}_{1}-\mathrm{C}_{4}$ \\
\hline
\end{tabular}

TABle 3: Kinetic constants, activation energies, and heats of reaction.

\begin{tabular}{lccc}
\hline Reaction $r$ & $\begin{array}{c}\left.k_{r}\right|_{823 \mathrm{~K}} \\
\left(\mathrm{~m}^{6} \mathrm{kmol}^{-1} \mathrm{~kg}_{\text {cat }}^{-1} \mathrm{~s}^{-1}\right)\end{array}$ & $\begin{array}{c}E_{r} \\
\left(\mathrm{~J} \mathrm{~mol}^{-1}\right)\end{array}$ & $\begin{array}{c}\Delta H_{r} \\
\left(\mathrm{~kJ} \mathrm{~kg}^{-1}\right)\end{array}$ \\
\hline Gas oil $\rightarrow$ gasoline & 20.4 & 57360 & 195 \\
Gas oil $\rightarrow$ light gases & 7.8 & 52750 & 670 \\
Gas oil $\rightarrow$ coke & 3.0 & 31820 & 745 \\
\hline
\end{tabular}

Eulerian approach, since equations for position, velocity, temperature, and masses of species are solved individually for each discrete particle.

The trajectory of each droplet is predicted solving the forces acting on the particle: the force of gravity and the drag with the gas phase. The Morsi and Alexander drag correlation for spherical particles [31] is used to model the drag coefficient.

According to the heat balance equations, these droplets are heated by the gas phase at higher temperatures, reducing their diameters until the liquid phase is completely vaporized. While the droplet temperature is below its vaporization temperature, convective heat is transferred from the continuous phase to the discrete phase and the droplet temperature is predicted using a heat balance. In this process, the heat transfer coefficient was estimated using the Ranz-Marshall correlation.

In the temperature range between the vaporization and the boiling temperature, mass is transferred from the liquid droplet to the continuous phase. The droplet temperature is then increased according to a heat balance that relates the droplet sensible heat change to the convective and latent heat transfer between the droplet and the continuous phase. When the droplet reaches the boiling temperature, it is assumed to be constant, and the diameter of the droplet begins to decrease until complete vaporization.

Since gas oil droplets rapidly vaporize, particle-particle interactions and effects of the particle volume fraction on the gas phase are negligible. The dispersion of particles due to turbulence in the fluid phase was also neglected.

A summary of the equations applied to model the discrete droplets can be seen in Table 4.

\section{Simulations}

The commercial code ANSYS FLUENT 12.0 was used to solve the proposed model. Appropriate user-defined functions were developed to implement the heterogeneous kinetics and the catalyst deactivation model into the software. FLUENT applies the finite volume method, where the domain is divided into a finite number of control volumes in which discrete variables are calculated. The pressure field was de-

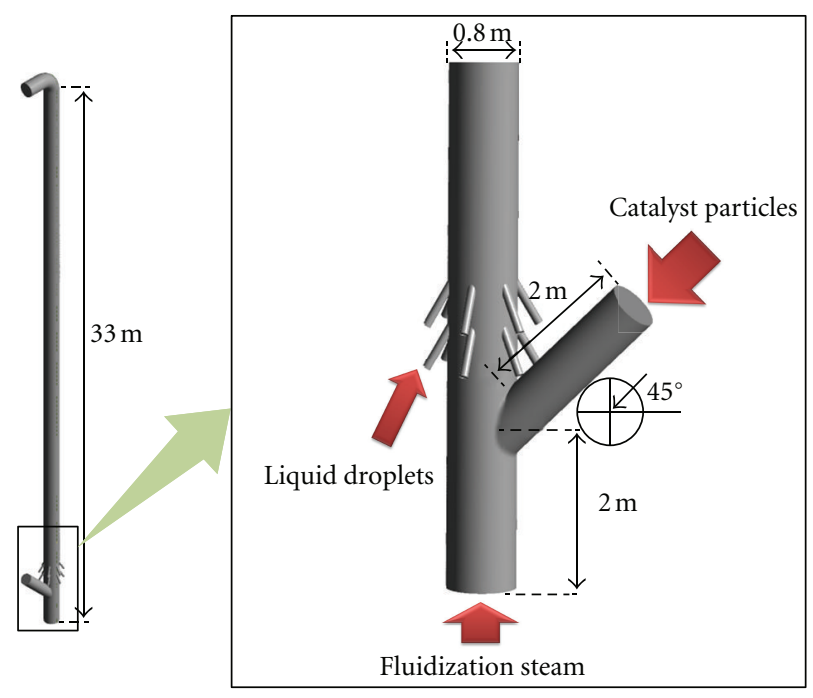

FIGURE 2: Geometry of the industrial riser.

termined using a pressure-based approach in which the continuity and momentum equations are manipulated to obtain an approximate equation for the pressure. The least squares cell-based method was applied to evaluate the diffusion and pressure gradients. The convective terms were discretized using a first-order upwind difference scheme, and transient terms were approximated using a first-order implicit scheme. The set of algebraic approximate equations was solved in a segregated way, using the simple algorithm for the pressure-velocity coupling [32].

The geometry of the simulated riser was proposed based on configurations found in the literature. The height and diameter of the column were based on an industrial riser reported by Ali et al. [14] and are shown in Table 6. Since they do not report details about the entrance and the outlet geometric configurations of that riser, a lateral entrance located $2 \mathrm{~m}$ from the base of the riser was adopted, for the catalyst particles feeding. Twelve 0.5 in diameter ducts at a $30^{\circ}$ angle to the main duct were used to feed in the liquid droplets. These configurations are commonly found in studies of CFB risers [33-35] and about the vaporization of the FCC feedstock $[24,36,37]$. This riser reactor geometry is illustrated in Figure 2.

Four different kinds of configurations for the riser outlet (Figure 3) are proposed in the present study, based on the works of Cheng et al. [1], Gupta and Berruti [2], Van Der Meer et al. [3], Harris et al. [4], Chan et al. [5], Pugsley et al. [9], and Van Engelandt et al. [10]. These configurations can be classified in two main groups: abrupt exits, in which there are sharp changes in the flow direction, inducing solids recirculation in the top section of the riser, and smooth exits, in which the flow changes according to the outlet bend, following a natural path.

The meshes applied consist of approximately 1.2 million hexahedral volumes depending on the configuration used for the riser exit. In order to guarantee that smaller control volumes are present where variable gradients are steeper, nonuniform grids are used. 
TABLE 4: Summary of Lagrangian equations.

\begin{tabular}{|c|c|c|}
\hline \multicolumn{3}{|c|}{ Lagrangian discrete phase model } \\
\hline Discrete phase trajectory: & $\frac{d x_{d}}{d t}=u_{d}$ & (A) \\
\hline Discrete phase velocity: & $\frac{d u_{d}}{d t}=\frac{\mathbf{g}\left(\rho_{d}-\rho_{g}\right)}{\rho_{d}}+F_{D}\left(u_{g}-u_{d}\right)$ & (B) \\
\hline Drag force: & $F_{D}=\frac{18 \mu_{g}}{\rho_{d} d_{d}^{2}} \frac{C_{D}^{d} \operatorname{Re}_{d}}{24}$ & (C) \\
\hline Droplet Reynolds number: & $\operatorname{Re}_{d}=\frac{\rho_{g} d_{d}\left|u_{d}-u_{g}\right|}{u_{\sigma}}$ & (D) \\
\hline Drag coefficient: & $C_{D}^{d}=a_{1}+\frac{a_{2}^{\mu_{g}}}{\operatorname{Re}}+\frac{a_{3}}{\operatorname{Re}^{2}}$ & (E) \\
\hline \multicolumn{3}{|l|}{ Heat balances: } \\
\hline$T_{d}<T_{\text {vap }}:$ & $m_{d} C_{p} \frac{d T_{d}}{d t}=h A_{d}\left(T_{\infty}-T_{d}\right)$ & (F) \\
\hline$T_{\text {vap }} \leq T_{d}<T_{\mathrm{bp}}$ & $m_{d} C_{p} \frac{d T_{d}}{d t}=h A_{d}\left(T_{\infty}-T_{d}\right)+\frac{d m_{d}}{d t} L$ & $(\mathrm{G})$ \\
\hline Heat transfer coefficient: & $h=\frac{\lambda}{d_{d}}\left(2.0+0.6 \operatorname{Re}_{d}^{1 / 2} \operatorname{Pr}^{1 / 3}\right)$ & $(\mathrm{H})$ \\
\hline Mass transfer: & $\frac{d m_{d}}{d t}=-k_{c}\left(C_{i, \text { surf }}-C_{i, \infty}\right) A_{d} M_{w, i}$ & (I) \\
\hline Mass transfer coefficient: & $k_{c}=\frac{D_{m, i}}{d_{d}}\left(2.0+0.6 \operatorname{Re}_{d}^{1 / 2} S c^{1 / 3}\right)$ & $(\mathrm{J})$ \\
\hline Droplet diameter variation: & $-\frac{d\left(d_{d}\right)}{d t}=\frac{4 k_{\infty}\left(1+0.23 \sqrt{\mathrm{Re}_{d}}\right)}{\rho_{d} C_{p, \infty} d_{d}} \ln \left[1+\frac{\left(T_{\infty}-T_{d}\right)}{L}\right]$ & $(\mathrm{K})$ \\
\hline
\end{tabular}

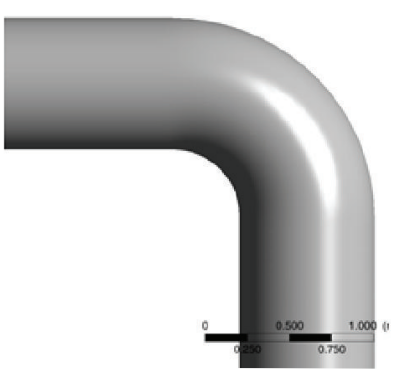

(A)

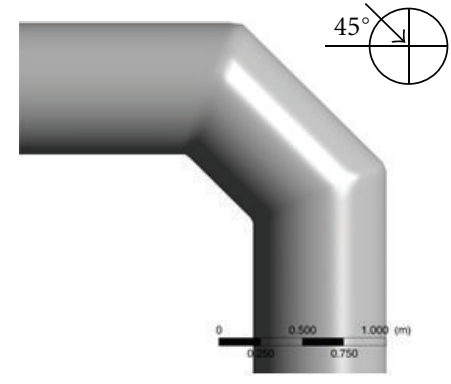

(B)

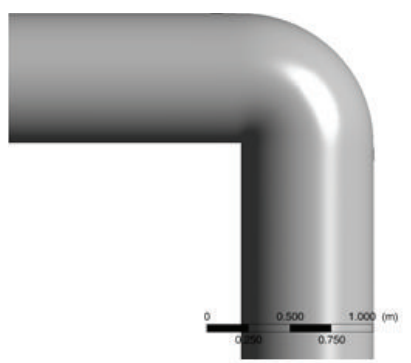

(C)

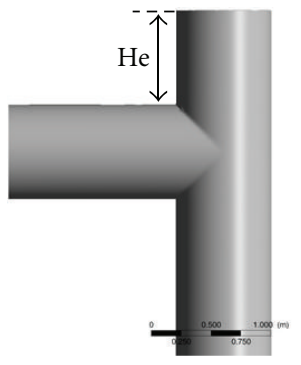

(D)

FIGURE 3: Exit configurations used in the simulations.

Since the heavy oil is not a pure component, its vaporization does not occur in a constant temperature. The properties of the liquid heavy oil and the values used for the range of temperature in which its vaporization occurs were taken from Nayak et al. [17] and are shown in Table 5.

The operating conditions used in the simulations are the same of the industrial riser reported by Ali et al. [14]. They are listed in Table 6 . About $7 \%$ of the total steam is fed with the catalyst particles at the lateral entrance, while the remaining steam is injected at the base of the reactor to help fluidization inside the riser. The physical properties and characteristics of the reactive species and the catalyst were taken from Martignoni and De Lasa [38] Van Landeghem et al. [19] and are listed in Table 7. The density of each reactive species was considered constant, independent of the system pressure and temperature. However, the density of the gas phase varies as the mixture composition changes with cracking reactions.

The simulations were carried out using a parallel code with 16 partitions on computers provided with Intel Xeon
$3 \mathrm{GHz}$ quad-core processors. The time step used for the solution was $10^{-3} \mathrm{~s}$. The convergence criterion for advancing in time was that the RMS residuals were less than $10^{-4}$. Initially $2 \mathrm{~s}$ of transient flow, in which just the steam and the catalyst particles were present, were calculated. After this time, the feed oil droplets started to be injected into the reactor and $8 \mathrm{~s}$ more of flow were simulated. Then the time average values of the flow variables were obtained for five additional seconds. About one day of calculation was necessary to predict each second of reactive flow for each simulation.

\section{Results and Discussion}

In the FCC process, heavy oil is injected into the riser reactor as liquid droplets. The cracking reactions are just initiated when these droplets vaporize and the reactive species are transferred from the liquid to the gas phase. Many studies about the FCC reactors, assume instantaneous vaporization of the oil. Lopes et al. [26], however, observed a significant 
TABLe 5: Physical properties of the liquid feed oil.

\begin{tabular}{lccccc}
\hline Density & $\begin{array}{c}\text { Vaporization } \\
\text { temperature }\end{array}$ & $\begin{array}{c}\text { Boiling } \\
\text { temperature }\end{array}$ & $\begin{array}{c}\text { Specific } \\
\text { heat }\end{array}$ & $\begin{array}{c}\text { Thermal } \\
\text { conductivity }\end{array}$ & $\begin{array}{c}\text { Latent } \\
\text { heat }\end{array}$ \\
\hline $870 \mathrm{~kg} \mathrm{~m}^{-3}$ & $530 \mathrm{~K}$ & $560 \mathrm{~K}$ & $1040 \mathrm{~J} \mathrm{~kg}^{-1} \mathrm{~K}^{-1}$ & $0.2 \mathrm{~W} \mathrm{~m}^{-1} \mathrm{~K}^{-1}$ & $4 \times 10^{5} \mathrm{~J} \mathrm{~kg}^{-1}$ \\
\hline
\end{tabular}

TABle 6: Geometric details and operating conditions of the industrial riser.

\begin{tabular}{lc}
\hline Riser height $(\mathrm{m})$ & 33 \\
Riser diameter $(\mathrm{m})$ & 0.8 \\
Mass flux of feed oil $\left(\mathrm{kg} \mathrm{m}^{-2} \mathrm{~s}^{-1}\right)$ & 40 \\
Catalyst-to-oil ratio $\left(\mathrm{kg}_{\text {cat }} / \mathrm{kg}_{\text {gasoil }}\right)$ & 7 \\
Steam $($ wt. $\%)$ & 7 \\
Feed oil temperature $(\mathrm{K})$ & 500 \\
Catalyst inlet temperature $(\mathrm{K})$ & 960 \\
Droplet inlet diameter $(\mu \mathrm{m})$ & 100 \\
\hline
\end{tabular}

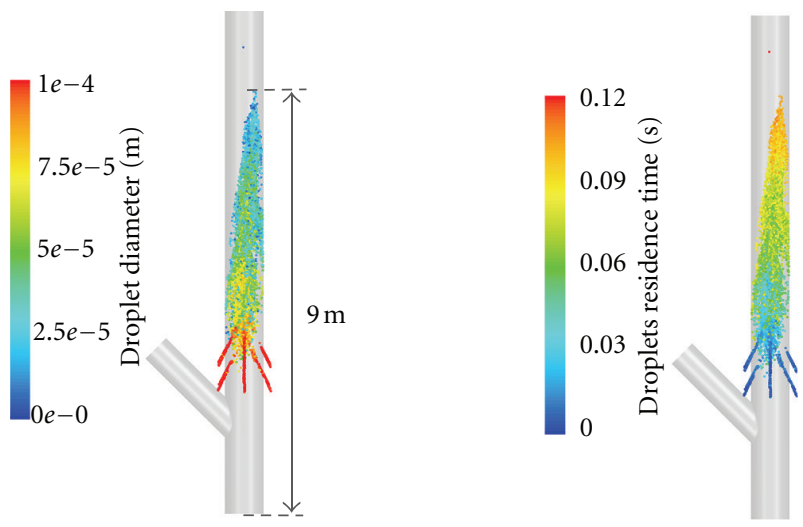

Figure 4: Droplets' diameter and residence time inside the reactor.

difference in product yields when the hypothesis of instantaneous vaporization was adopted and when this phenomenon is modeled. Based on these results, the vaporization of the droplets was taken into account in the present work. The diameter of the droplets and their residence time inside the reactor are shown in Figure 4. These results were collected $10 \mathrm{~s}$ after the start of the liquid injection. At this moment, the complete vaporization of the liquid droplets takes place at a height of approximately $9 \mathrm{~m}$.

The maximum residence time of the droplets before they are completely vaporized was monitored along the time. As can be seen in Figure 5, the maximum value observed was $0.18 \mathrm{~s}$, obtained $1.25 \mathrm{~s}$ after the start of the liquid droplets injection. After this time, the maximum residence time decreases, reaching an average value of $0.12 \mathrm{~s}$. According to Liu and Han [39] (cited in [37]) the complete vaporization of the charge is completed within $0.2 \mathrm{~s}$, in risers of typical FCC units. This shows that the model used in the simulations is appropriate to describe the phenomenon of vaporization. The number of liquid droplets present in the system follows the same trend (Figure 6), reaching its maximum value about two seconds after the beginning of the charge injection into the reactor. The average number of liquid droplets inside the

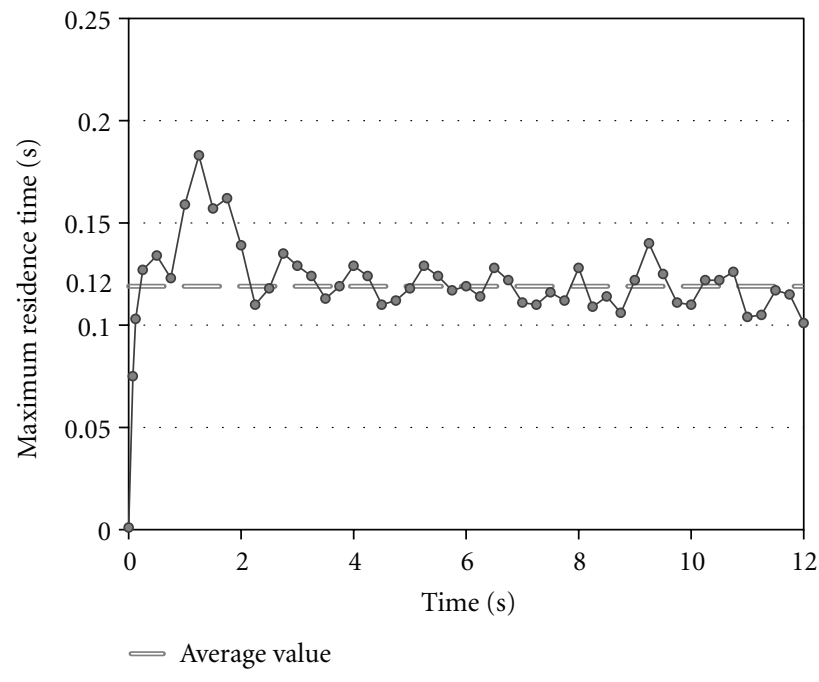

Figure 5: Maximum residence time of the droplets.

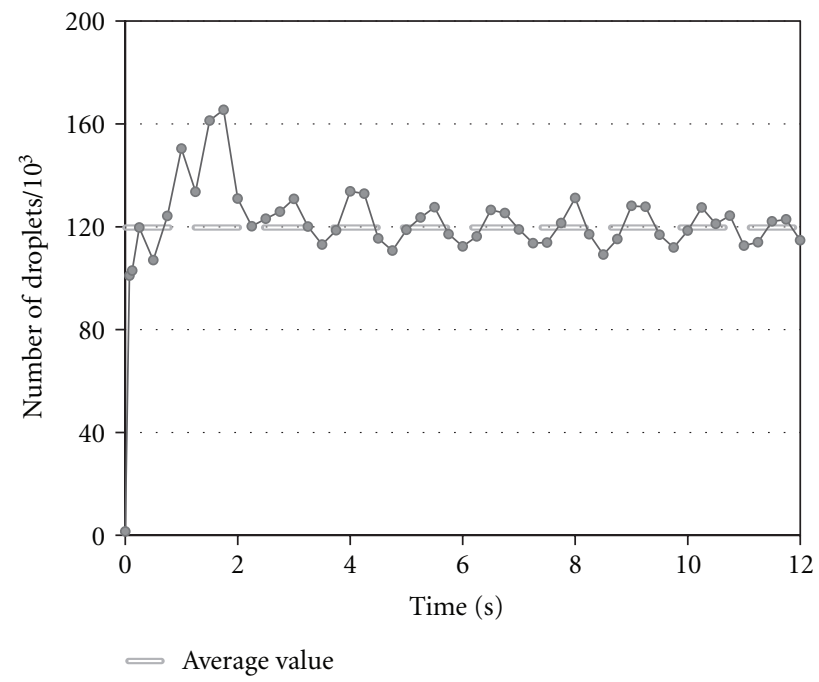

FIGURE 6: Instantaneous number of droplets.

riser reactor is about 120 thousand. These results emphasize the importance of simulating the vaporization of the liquid oil charge stock in the FCC process.

The inlet zone of the riser is a very complex part of the reactor, where intense turbulence and flow inhomogeneities are observed. A detailed study about this region was performed by Lopes et al. [22], where it is shown that, depending on the operating conditions applied, the inlets arrangement can affect the flow patterns along all riser height. Extremely complex hydrodynamics has been also observed in the outlet 
TABle 7: Physical properties of reactive species and catalyst.

\begin{tabular}{|c|c|c|c|c|c|}
\hline Species & Vaporized gas oil & Gasoline & Light gases & Coke & Catalyst \\
\hline Density $\left(\mathrm{kg} \mathrm{m}^{-3}\right)$ & 6 & 1.5 & 0.8 & 1400 & 1400 \\
\hline Specific heat $\left(\mathrm{J} \mathrm{kg}^{-1} \mathrm{~K}^{-1}\right)$ & 2420 & 2420 & 2420 & 1090 & 1090 \\
\hline Thermal conductivity $\left(\mathrm{W} \mathrm{m}^{-1} \mathrm{~K}^{-1}\right.$ ) & 0.025 & 0.025 & 0.025 & 0.045 & 0.045 \\
\hline Molecular weight $\left(\mathrm{kg} \mathrm{kmol}^{-1}\right)$ & 400 & 100 & 50 & 400 & - \\
\hline Particle diameter $(\mu \mathrm{m})$ & - & - & - & - & 65 \\
\hline Viscosity $\left(\mathrm{kg} \mathrm{m}^{-1} \mathrm{~s}^{-1}\right)$ & $5.0 \times 10^{-5}$ & $1.6 \times 10^{-5}$ & $1.6 \times 10^{-5}$ & $1.7 \times 10^{-5}$ & $1.7 \times 10^{-5}$ \\
\hline
\end{tabular}

TABLE 8: Definition of simulated cases.

\begin{tabular}{lcc}
\hline Case & Configuration $^{1}$ & He $(\mathrm{m})^{1}$ \\
\hline 1 & A & - \\
2 & B & - \\
3 & C & - \\
4 & D & 0 \\
5 & D & 0.8 \\
\hline
\end{tabular}

${ }^{1}$ According to Figure 3.

region of $\mathrm{CFB}$ risers $[3,9,10]$, which can affect the reactor efficiency.

In order to verify the influence of different riser exit configurations on reactor performance, five cases were initially proposed. The four geometric configurations shown in Figure 3 were tested. Two variations of the abrupt $\mathrm{T}$ exit (Figure 3(d)) with different projected heights $(\mathrm{He})$ were also simulated. The definition of each case according to the configuration applied in the simulations can be seen in Table 8.

The effect of the exits on the flow was evaluated using parameters reported by Van Der Meer et al. [3] and Schut et al. [28]. Their definitions are listed in Table 9. These parameters help to quantify some important characteristics of the flow in the riser, such as core-annulus patterns, the increase in the downflux in abrupt exit risers, and the asymmetry of the flow.

The values of parameter $H_{\mathrm{bf}}$ obtained for each of the five cases are shown in Table 10. For Cases 1 and 2 these values are zero, indicating that under the conditions applied, there is no solids reflux when configurations $\mathrm{A}$ and $\mathrm{B}$ (Figure 3) are used. These results help to characterize these configurations as smooth exits, since they do not restrict the solids flux. Despite the similarity between configurations A and $\mathrm{C}$ (Figure 3), the case simulated using the latter (Case 3) provided some solids backmixing $\left(H_{\mathrm{bf}}=0.036\right)$ induced by the sharp right angle in this configuration. The maximum reflux of particles was obtained when the T-shape exit with a projected height of $0.8 \mathrm{~m}$ was used (Case 5). In this case, solids flowing in counter current to the main flow reached a distance of $9.75 \mathrm{~m}$ from the top of the riser, corresponding to about $28 \%$ of its total height.

The movement of solid particles in center planes at the outlet bends is represented as velocity vectors in Figure 7. As shown previously, no solids reflux can be observed in Cases 1 and 2, justifying the zero value for parameter $H_{\mathrm{bf}}$ obtained in these cases. The internal sharp right angle seen in Cases 3, 4, and 5 induces the formation of recirculation areas just after the bend. A second vortex is formed at the riser wall opposite the outlet opening in Cases 4 and 5, in which the exit is at sharp right angles also at the outer side of the bend. The higher the downward flow of the particles is, the more intense the restriction on the direct flow is, causing an increase in its velocity in the central region of the riser.

Harris et al. [40] described a physical mechanism to help to explain the motion of solids at a riser exit. They postulate that when solids follow a curved path of mean radius $R$ at the exit, the centrifugal acceleration is balanced against the average component of the acceleration due to gravity acting toward the center of the bend. In regions where the solids slow down due to geometric accidents at the exit bend, gravity overlaps centrifugal acceleration, causing a change in trajectory and creating recirculation zones, as observed in the simulated cases.

In Figure 8, solids volume fraction fields are shown for the five simulated cases, where an accumulation of particles at the top of the riser can be seen. As the particle density is much higher than the gas mixture density, the particle inertia is also higher, which means that particles are easily separated from the gas stream near the exit, even at outlets considered smooth. In addition, the abrupt exits create an extra resistance, causing an increase in the concentration of this phase at the outlet bend. As a result, the average solids fraction and the annulus thickness near the top of the riser are much higher in Cases 4 and 5, in which the solids recirculation is also higher. As observed in other studies [10, 11 ], for risers with abrupt exits the accumulation of solids is more pronounced at the side opposite to the outlet than the side of the riser at which the outlet bend is positioned.

The accumulation of solids observed in the cases with abrupt exits results in a densification of the annulus structure near the outlet bends. This is confirmed in Figure 9, which shows the solids volume fraction in radial planes located at heights of 20 and $32 \mathrm{~m}$ in Cases 1 and 5 . At a height of $20 \mathrm{~m}$ the core-annulus patterns are very similar in both cases. However, when approaching the outlet bend there is a coarsening of the annular structure in Case 5 resulting from the solids recirculation observed in this case.

In order to analyze the solids accumulation near the exit of the risers with different configurations, average values of the solids volume fraction in transversal planes were taken along the riser height. The shape of the average solids holdup profile is a good indicator of how the exit effects propagate down the riser. As shown in Figure 10, in all cases studied 
TABLE 9: Parameters applied to evaluate the influence of the exits on the flow.

\begin{tabular}{ll}
\hline Parameter & Definition \\
\hline$H_{\mathrm{bf}}$ & $\begin{array}{l}\text { Backflux relative height: distance from the top of the riser traveled by the particulate phase in downward motion } \\
\text { divided by riser height. }\end{array}$ \\
$k_{a}$ & $\begin{array}{l}\text { Exit reflection coefficient: fraction of the riser transversal area within which solids move downwards. } \\
k_{a}^{*}\end{array}$ \\
$\begin{array}{l}\text { Asymmetry of } k_{a} \text { : defined by the difference between the fraction of the area with negative velocity of solids located at the } \\
\text { positive and the negative side of the } x \text {-axis. }\end{array}$ \\
Film thickness of downflow: given by $D\left(1-\sqrt{1-k_{a}}\right) / 2[28]$. \\
\hline
\end{tabular}

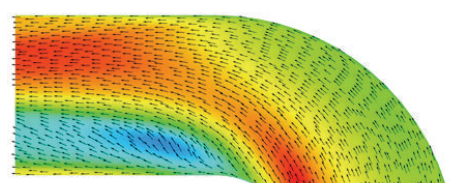

(1)
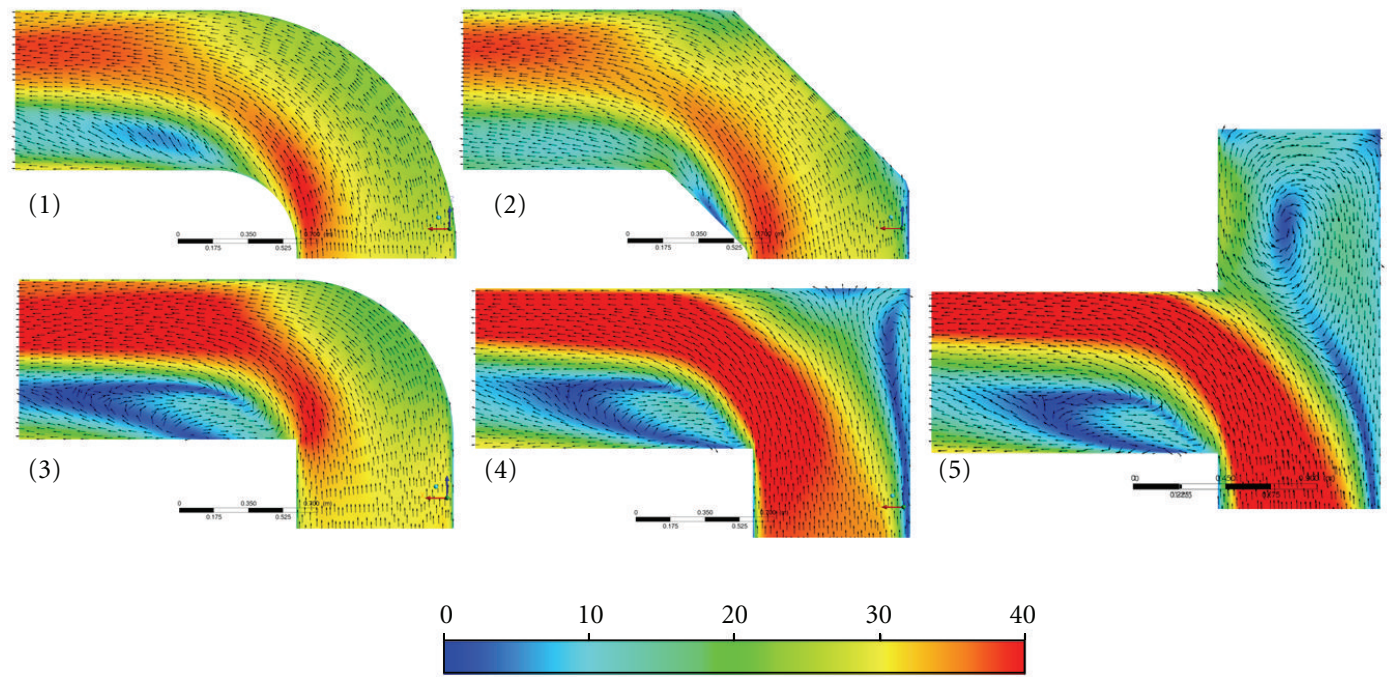

Velocity of the solid phase $(\mathrm{m} / \mathrm{s})$

FIGURE 7: Solid phase velocity and movement.
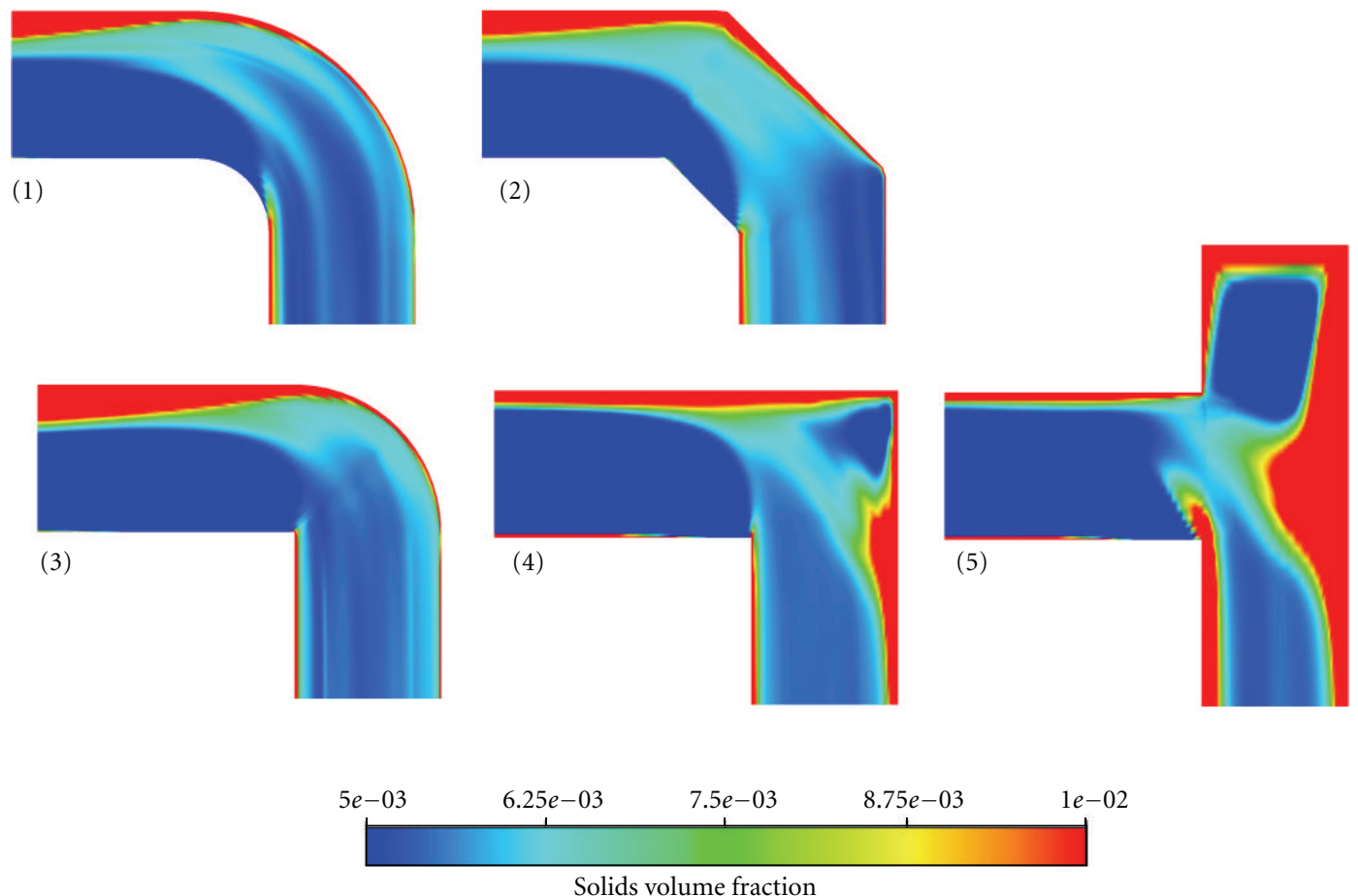

FIGURE 8: Solids volume fraction profiles at the exits. 

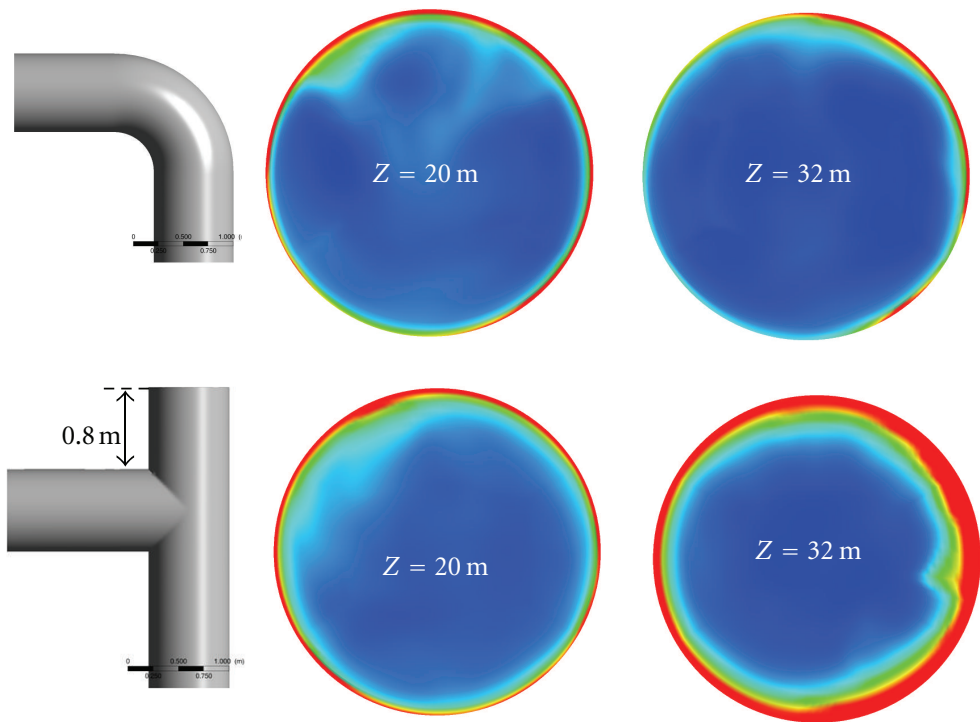

$5 e-03 \quad 8.75 e-03 \quad 1.25 e-021.62 e-02 \quad 2 e-02$

Solids volume fraction

FIGURE 9: Core-annulus patterns.

TABLE 10: $H_{\mathrm{bf}}$ obtained for each case.

\begin{tabular}{lc}
\hline Case & $H_{\mathrm{bf}}$ \\
\hline 1 & 0.000 \\
2 & 0.000 \\
3 & 0.036 \\
4 & 0.117 \\
5 & 0.279 \\
\hline
\end{tabular}

the average volume fraction initially decreases due to the expansion of the gas phase caused by the catalytic cracking of the large hydrocarbon molecules into smaller ones during the process. The profiles continue decreasing in the cases with smooth exits, but this tendency suddenly change in risers with abrupt exits, creating a profile described as C-shape. The more restrictive the exit configuration is, the further down the riser its effect propagates. This trend is consistent with results reported in many studies on CFB risers [6, 40-42].

The recirculation of solids observed in the risers with abrupt exits results in an increase in their residence time inside the reactor. As the solid phase is treated in this study as a continuous fluid using Eulerian approach, it is not possible to calculate exactly the residence time of each particle in the system. In order to estimate an approximated time, a methodology applied by liu and Tilton [43], in which average values are estimated, was applied. Initially, a new property $(\Psi)$, with unit of second, was defined for the solid phase. An user-defined scalar (UDS) transport equations was then introduced into the model in the form [32]

$$
\frac{\partial}{\partial t}\left(\varepsilon_{s} \rho_{s} \Psi\right)+\nabla \cdot\left(\varepsilon_{s} \rho_{s} \mathbf{u}_{s} \Psi\right)=\nabla \cdot\left(\varepsilon_{s} \Gamma^{\Psi} \nabla \Psi\right)+S^{\Psi} .
$$

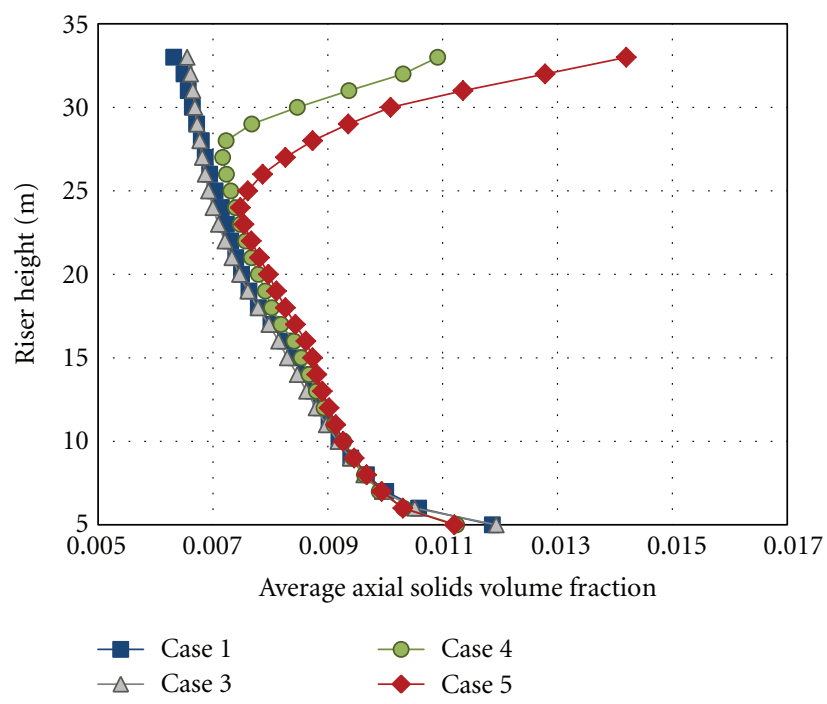

FIGURE 10: Average solids volume fraction in cross-section planes along the height.

If the diffusive terms were neglected, the scalar just propagates with the time and the movement of the solid phase. The source term was then implemented via user defined-function (UDF) as

$$
S^{\Psi}=\varepsilon_{s} \rho_{s} .
$$

As the solution advances in time, this value is added to the scalar. Thus, assuming that this property is equal to zero at the solids entrance and in the problem initialization, a cumulative function that propagates with the time and the solids movement is created. This enables an estimation 
TABLE 11: Residence time.

\begin{tabular}{lc}
\hline Case & Mean value $(\mathrm{s})$ \\
\hline 1 & 1.943 \\
5 & 2.299 \\
\hline
\end{tabular}

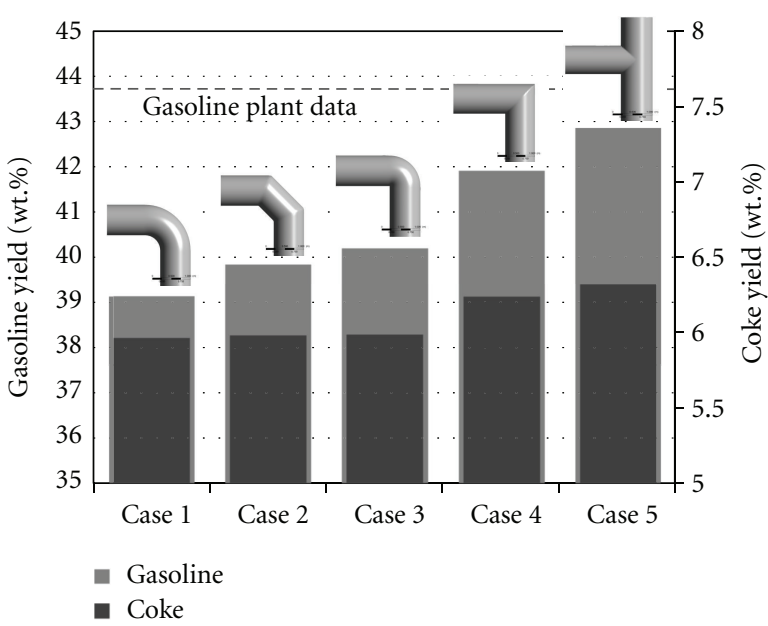

FIGURE 11: Gasoline and coke yields at the riser outlet.

of an approximated residence time of the solid particles. In Table 11 the solids mean residence time obtained for Cases 1 and 5 is shown. When the abrupt T-shape exit with a projected height of $0.8 \mathrm{~m}$ is applied in the FCC riser simulation, the mean residence time is increased by about $18 \%$ in relation to the value obtained for the smoother exit. This difference can influence the reaction time, increasing the conversion rates.

The gasoline and coke yields at the riser outlet obtained in the simulated cases are shown in Figure 11. This value increases as resistance to the flow becomes more intense and the solids recirculation increases. Comparing Cases 1 and 5, there is an increase of about $4 \%$ in the gasoline yield.

In order to validate the simulated results with the data reported by Ali et al. [14], the operating conditions and the equipment dimensions used were the same as those of their industrial riser. Since Ali et al. [14] do not report details of the exit configuration of this riser, several configurations were tested in the simulations. However, it is known that the T-shape design, as used in the simulation of Case 5 , is the most common configuration found in industry, since it reduces the erosive particle impingement on the roof of the riser. As can be seen in Figure 11, the value of the gasoline yield which most closely approximates the industrial value $(43.9 \%)$ was the one obtained in the simulation of Case 5 , with a deviation of only about $2 \%$.

Average values of gasoline yield were also taken in transversal planes along the riser height in Cases 1 and 5, as shown in Figure 12. Similarly to the profiles of average solids volume fraction (Figure 10), the gasoline yield profiles coincide up to a certain height, at which point the tendency in the riser changes with the abrupt T-shape exit.

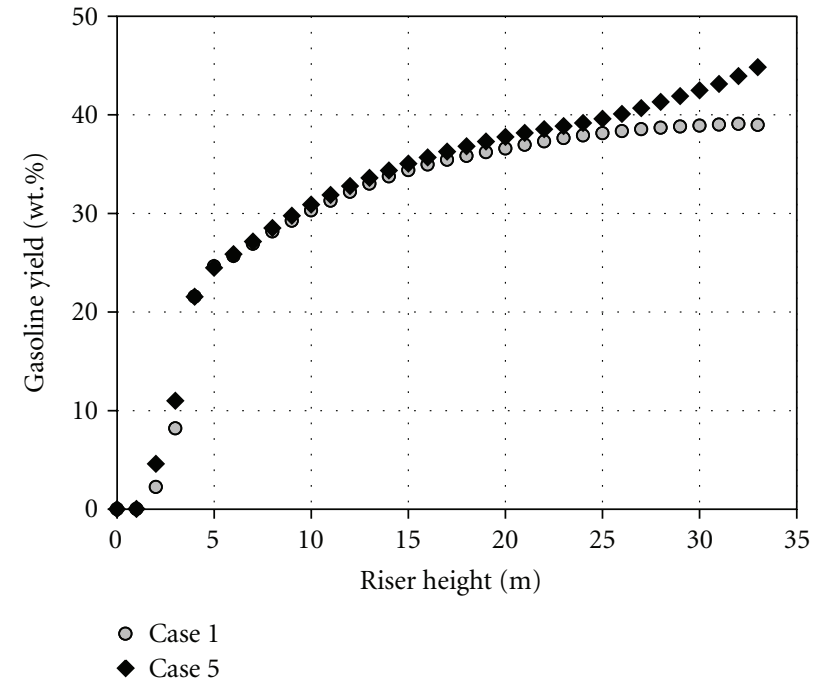

FIGURE 12: Average gasoline yield in cross-section planes along the height.

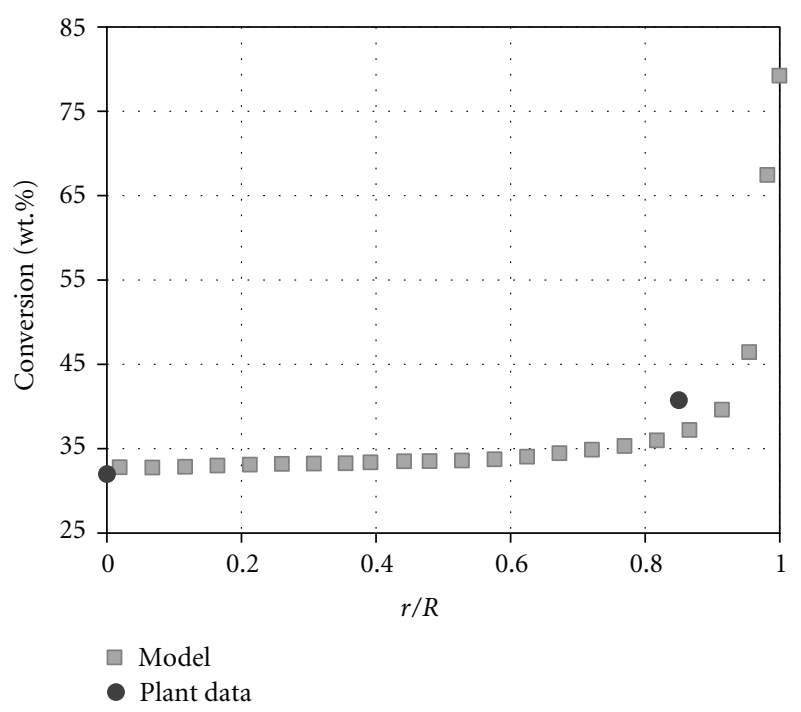

FIgURE 13: Radial profile of cracking conversion.

The results obtained for the cracked hydrocarbons conversion in the simulation of Case 5 were also compared with plant data sampled by Martin et al. [41] at $4 \mathrm{~m}$ above the upper feedstock injection point at two locations along the riser radius (Figure 13). Although they do not provide information on the geometry and operating conditions of the industrial plant for which the data were taken, the comparison of simulated and experimental local cracking conversion showed good agreement. It can be clearly seen that the conversion is higher toward the wall. This can be attributed to the larger catalyst concentration, smaller velocity and higher temperature near the wall, and to the catalyst/gas backmixing at this region. The mass fractions of coke and gasoline in the outlet region for the Cases 1 and 5 are shown in Figure 14, where noticed higher values can be 
(A)
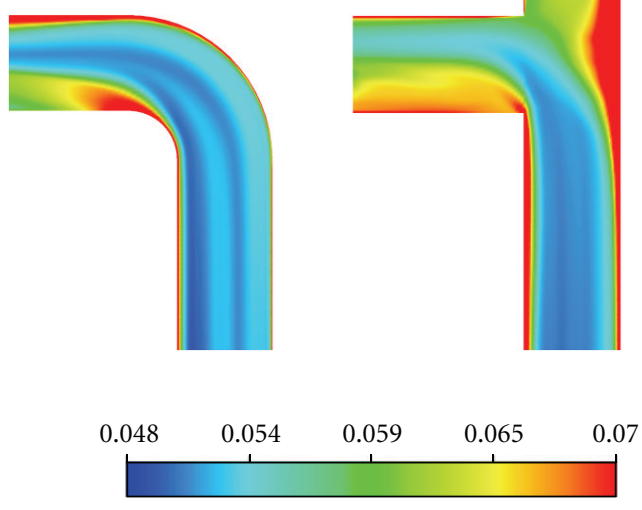

Mass fraction of coke
(A)

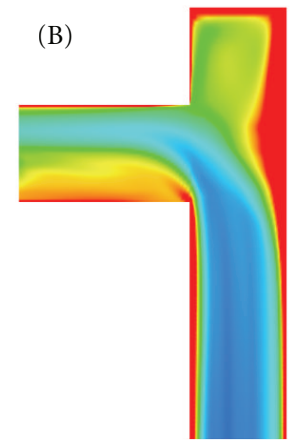

0.07

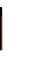

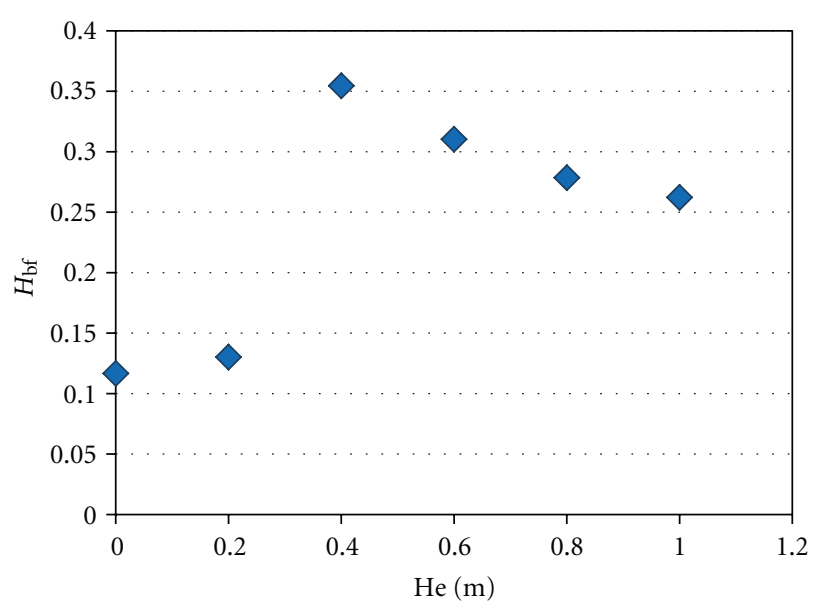

Figure 15: $H_{\text {bf }}$ parameter obtained for different projected heights.

in the zones in which higher recirculation of solids was found (Figure 8).

As shown above, the geometries applied in the simulation of Cases 1, 2, and 3 (configurations A, B and C in Figure 3) have very small or null reverse flow of solids and therefore can be characterized as smooth exits for the operating conditions and feedstock used in the simulations. In the cases in which the type $\mathrm{D}$ configuration with different projected heights is used, there is significant solids recirculation which affects the flow even far from the outlet bend, and therefore it can be classified as abrupt exits. In order to determine the response of the flow to the variation in the projected height of configuration $\mathrm{D}$, the simulation of four new cases, in which He was assumed to be $0.2 \mathrm{~m}, 0.4 \mathrm{~m}, 0.6 \mathrm{~m}$, and $1.0 \mathrm{~m}$, was proposed.

The relative height of backflux (represented by parameter $H_{\text {bf }}$ ) was estimated for each new case, as can be seen in Figure 15. As He increases, there is initially a sharp increase

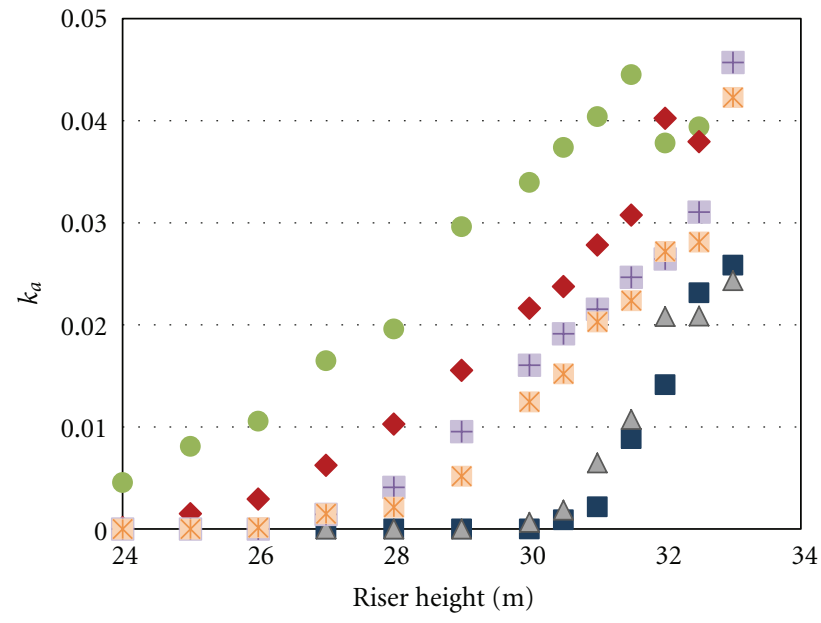

$$
\begin{aligned}
& \square \mathrm{He}=0 \mathrm{~m} \leadsto \mathrm{He}=0.6 \mathrm{~m} \\
& \triangle \mathrm{He}=0.2 \mathrm{~m} \quad+\mathrm{He}=0.8 \mathrm{~m} \\
& \text { - } \mathrm{He}=0.4 \mathrm{~m} \quad \mathbb{H e}=1 \mathrm{~m}
\end{aligned}
$$

FIGURE 16: $k_{a}$ parameter obtained along the height for different projected heights.

in the value of $H_{\mathrm{bf}}$, which reaches maximum value at $\mathrm{He}=$ $0.4 \mathrm{~m}$, where the solids downward flow is detected at a distance from the outlet bend corresponding to about 35\% of the length of the riser. Above $\mathrm{He}=0.4 \mathrm{~m}$, the value of $H_{\mathrm{bf}}$ decreases, tending to stabilize at about 0.25 .

The parameters which represent the fraction of crosssectional area of the riser in which there is a downward flow of solids $\left(k_{a}\right)$ and the asymmetry of the flow $\left(k_{a}^{*}\right)$ were also estimated for each of these cases. They are shown in Figures 16 and 17 according to riser height. There is an increase in the value of $k_{a}$ along the height of the reactor. As shown in Figure 10, the solids accumulation in risers with abrupt exits leads to the enlargement of the annular 


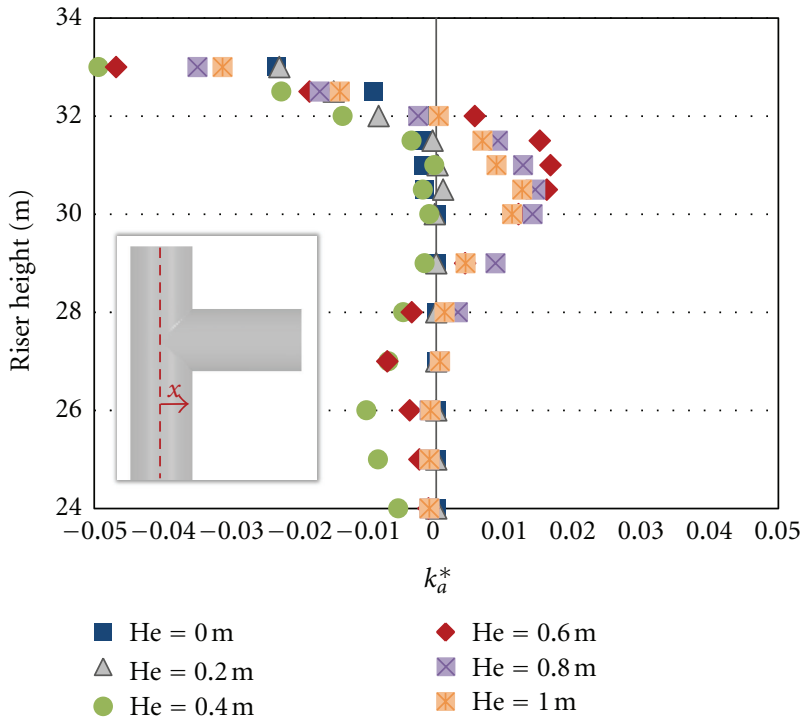

FIGURE 17: $k_{a}^{*}$ parameter obtained along the height for different projected heights.

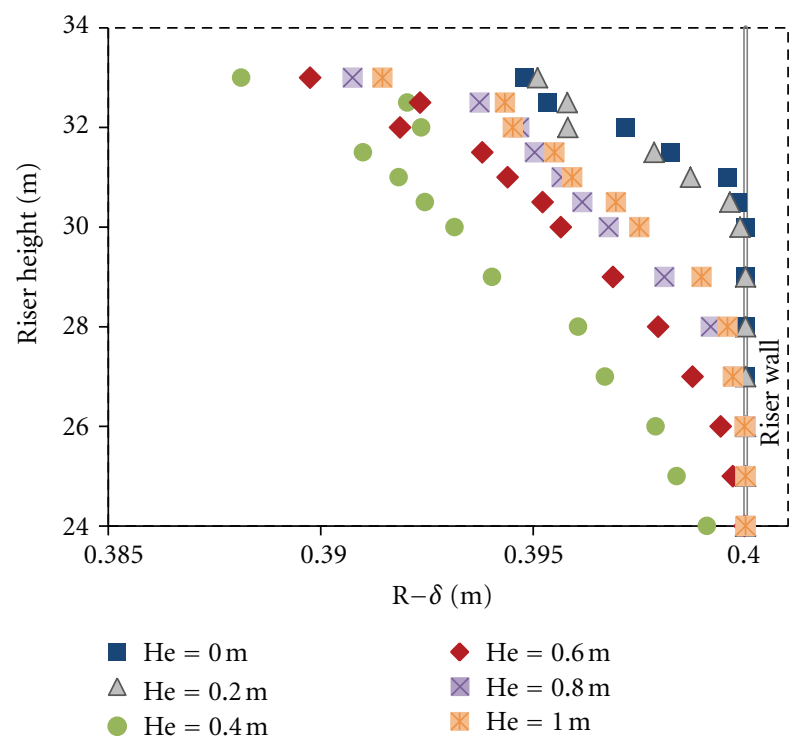

FIgURE 18: Film thickness of downflow.

structure, consequently increasing the fraction of the area occupied by the downward flowing solids. The configuration with $\mathrm{He}=0.4 \mathrm{~m}$ has the highest values of $k_{a}$ even below a height of $24 \mathrm{~m}$, which indicates that the solids recirculation is more intense for this case, corroborating the results shown in Figure 15.

Analysis of parameter $k_{a}^{*}$ (Figure 17) shows that the flow is more asymmetric in regions far from the outlet bend for the exit with $\mathrm{He}=0.4 \mathrm{~m}$. Moreover, the displacement of this parameter to the negative side of axis $x$ above a height of $32 \mathrm{~m}$ in all cases confirms the patterns seen in Figure 8, in which there is a region of solids accumulation on the side opposite to the outlet bend when abrupt exits are used. These

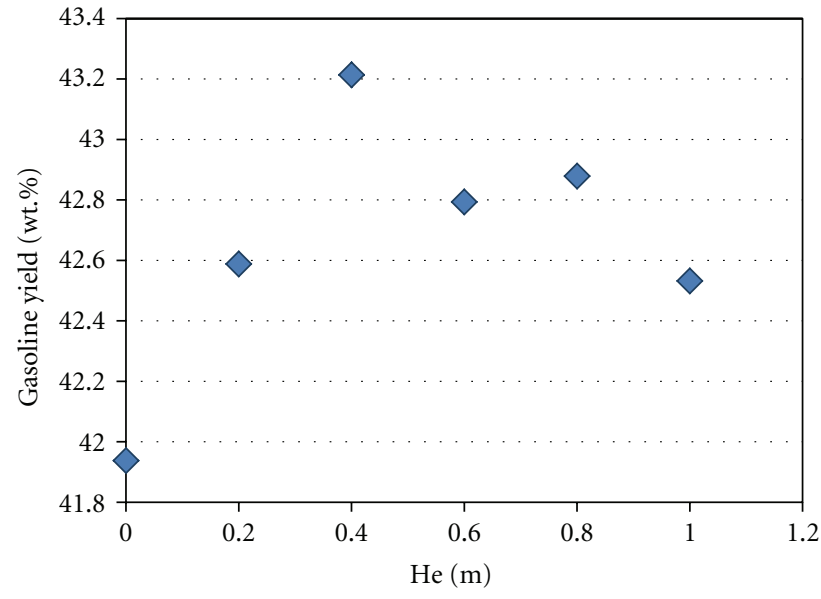

Figure 19: Gasoline yields at the riser outlet.

asymmetric patterns near the inner top side wall were also observed by Wang et al. [44] in an experimental study of gassolid circulating fluidized bed using Electrical Capacitance Volume Tomography (ECVT).

The film thickness of the downflow $(\delta)$ is indicated in Figure 18, which shows the values of $R-\delta$ along the riser height. In all cases, this film is thickest immediately below the outlet bend at a height of $33 \mathrm{~m}$ and decreases downward from there. Because of the high solids reflux rate found in the riser with a projected height of $0.4 \mathrm{~m}$, the values found for $\delta$ are also higher in this case.

In Figure 19 the average values for gasoline yield at the riser outlet obtained for the risers with different projected height are shown. These results follow almost the same tendency as that observed in Figure 15, indicating that solids recirculation increases the formation of gasoline fractions in these cases.

Under the flux conditions used in the present study, the increase in solids residence time improves the reactor efficiency, mainly in cases with a high solids reflux ratio. In addition, as the catalytic reactions depend on the presence of catalyst in the system and the rate of reaction is linearly dependent on its concentration, the increase in the solids volume fraction at the top section of the riser results in an increase in the reaction rates with higher product yields.

\section{Conclusions}

In the present work, different outlet bend designs for an industrial FCC riser were proposed to study their influence on the dynamic of the flow and consequently on reactor efficiency. A three-dimensional and three-phase reactive flow model was used in order to predict most of the phenomena present in this complex process.

As can be seen from the simulation results, small changes in the geometry of the reactor had a significant effect on the flow patterns and therefore on the product yields. The use of abrupt exits results in solids backmixing, enhancing the residence time of the catalyst and increasing its concentration near the top of the riser. An area of densification is then 
created near the exit, which, depending on the severity of the exit restriction, extends along the length of the riser.

The increase in the amount of catalyst particles favors the heterogeneous FCC reactions, which are proportional to the solids concentration in the system. As a result, risers with abrupt exits, in addition to reduce the erosive particle impingement on the roof of the equipment, had higher gasoline yields. The T-shape exit with a projected height of $0.4 \mathrm{~m}$ gave the highest value for this variable (closer to the industrial data), indicating that this outlet configuration improves the reactor efficiency under the conditions applied in the present study.

It is important to emphasize that computer simulations require detailed information about the feedstock and the catalyst particles as well as the reactor design. This information is rarely found in experimental studies on industrial reactors, making necessary the adoption of some assumptions to make possible their simulation. Nevertheless, the models used and the material properties chosen gave results close to the industrial data obtained under the same operating conditions applied in the simulations, especially when configurations commonly found in industrial plants were applied.

\section{Notations}

\begin{tabular}{|c|c|}
\hline$a_{i=1,2,3}$ : & Empirical model constants [-] \\
\hline$A:$ & Superficial area $\left[\mathrm{m}^{2}\right]$ \\
\hline$C:$ & Molar concentration $\left[\mathrm{kmol} \mathrm{m}^{-3}\right]$ \\
\hline$C_{D}:$ & Drag coefficient $[-]$ \\
\hline$C_{G}:$ & Constant of elasticity modulus function $[\mathrm{Pa}]$ \\
\hline$C_{p}:$ & Specific heat $\left[\mathrm{J} \mathrm{kg}^{-1} \mathrm{~K}^{-1}\right]$ \\
\hline$C_{\mu}:$ & Model constant \\
\hline$d:$ & Diameter $[\mathrm{m}]$ \\
\hline$D_{m}:$ & Mass diffusivity $\left[\mathrm{m}^{2} \mathrm{~s}^{-1}\right]$ \\
\hline$e_{s s}:$ & Coefficient of restitution $[-]$ \\
\hline$E:$ & Activation energy $\left[\mathrm{J} \mathrm{mol}^{-1}\right]$ \\
\hline$F_{D}:$ & $\begin{array}{l}\text { Drag force between droplets and the gas phase } \\
{\left[\mathrm{s}^{-1}\right]}\end{array}$ \\
\hline g: & Gravitational acceleration $\left[\mathrm{m}^{2} \mathrm{~s}^{-1}\right]$ \\
\hline G: & Elasticity modulus $[\mathrm{Pa}]$ \\
\hline$g_{0, s s}:$ & Radial distribution function $[-]$ \\
\hline$h:$ & Heat transfer coefficient $\left[\mathrm{W} \mathrm{m}{ }^{-2} \mathrm{~K}^{-1}\right]$ \\
\hline$H:$ & Static enthalpy $\left[\mathrm{J} \mathrm{mol}^{-1}\right]$ \\
\hline$k:$ & $\begin{array}{l}\text { Thermal conductivity }\left[\mathrm{W} \mathrm{m}^{-1} \mathrm{~K}^{-1}\right] \text { or } \\
\text { turbulent kinetic energy }\left[\mathrm{m}^{2} \mathrm{~s}^{-2}\right]\end{array}$ \\
\hline$k_{c}:$ & Mass transfer coefficient $\left[\mathrm{m} \mathrm{s}^{-1}\right]$ \\
\hline$k_{r}:$ & Reaction kinetic constant $\left[\mathrm{m}^{3} \mathrm{kmol}^{-1} \mathrm{~s}^{-1}\right]$ \\
\hline$k_{r}^{0}$ : & Preexponential factor $\left[\mathrm{m}^{3} \mathrm{kmol}^{-1} \mathrm{~s}^{-1}\right]$ \\
\hline$K_{c}:$ & Deactivation constant $\left[\mathrm{kg}_{\mathrm{cat}} \mathrm{kmol}^{-1}\right]$ \\
\hline$K_{i=1,2,3,4}:$ & Model functions \\
\hline$L:$ & Latent heat of vaporization $\left[\mathrm{kJ} \mathrm{kg}^{-1}\right]$ \\
\hline$m:$ & Mass $[\mathrm{kg}]$ \\
\hline$M_{w}:$ & Molecular mass $\left[\mathrm{kg} \mathrm{kmol}^{-1}\right]$ \\
\hline$n:$ & Reaction order $[-]$ \\
\hline$n_{d}:$ & Droplets density $\left[\mathrm{m}^{-3}\right]$ \\
\hline$p:$ & Static pressure $[\mathrm{Pa}]$ \\
\hline
\end{tabular}

$p_{s}:$ Solids pressure $[\mathrm{Pa}]$

$P^{k}$ : Shear production of turbulence $\left[\mathrm{Pa} \mathrm{s}^{-1}\right]$

Pr: Prandtl number [-]

$q_{1}$ : Specific coke concentration $\left[\mathrm{kmol} \mathrm{kg}_{\text {cat }}^{-1}\right]$

$R$ : Reaction rate $\left[\mathrm{kmol} \mathrm{m}^{-3} \mathrm{~s}^{-1}\right]$ or universal gas constant $\left[\mathrm{J} \mathrm{mol}^{-1} \mathrm{~K}^{-1}\right]$

$\hat{R}$ : Net reaction rate of formation/consumption $\left[\mathrm{kmol} \mathrm{m}^{-3} \mathrm{~s}^{-1}\right]$

Re: Reynolds number [-]

S: Source term

$T$ : Static temperature $[\mathrm{K}]$

$\mathbf{u}$ : Velocity vector $\left[\mathrm{m} \mathrm{s}^{-1}\right]$

$\mathbf{u}^{\prime}$ : Velocity fluctuation $\left[\mathrm{m} \mathrm{s}^{-1}\right]$

$x$ : Position $[\mathrm{m}]$

$Y$ : Mass fraction $[-]$.

\section{Greek Letters}

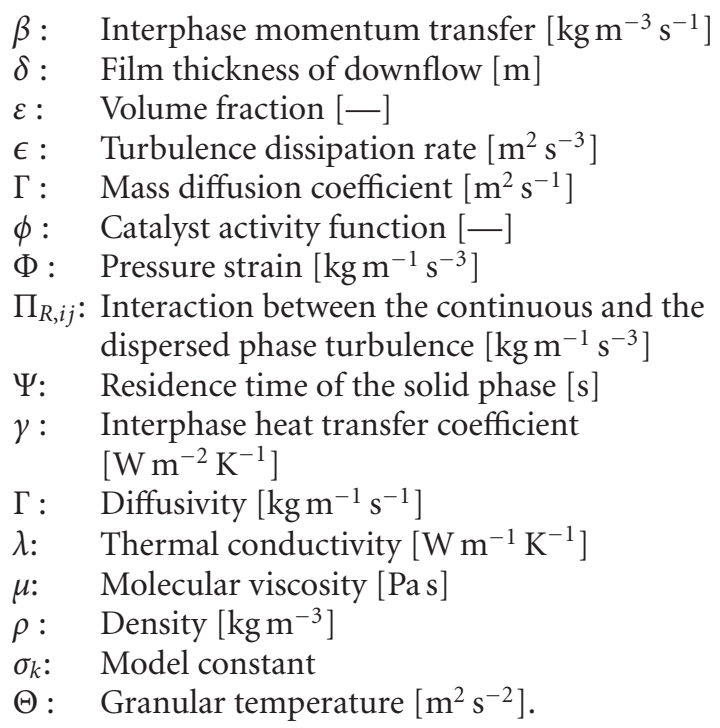

\section{Subscripts}

$\begin{array}{ll}d: & \text { Droplet } \\ g: & \text { Gas phase } \\ i: & \text { Species or lump } \\ \text { max: } & \text { Maximum } \\ r: & \text { Reaction } \\ s: & \text { Solid phase } \\ \text { surf: } & \text { Surface } \\ \infty: & \text { Bulk. }\end{array}$

\section{Acknowledgment}

The authors gratefully acknowledge the financial support of PETROBRAS for this research. 


\section{References}

[1] Y. Cheng, F. Wei, G. Yang, and J. Yong, "Inlet and outlet effects on flow patterns in gas-solid risers," Powder Technology, vol. 98, no. 2, pp. 151-156, 1998.

[2] S. K. Gupta and F. Berruti, "Evaluation of the gas-solid suspension density in CFB risers with exit effects," Powder Technology, vol. 108, no. 1, pp. 21-31, 2000.

[3] E. H. Van Der Meer, R. B. Thorpe, and J. F. Davidson, "Flow patterns in the square cross-section riser of a circulating fluidised bed and the effect of riser exit design," Chemical Engineering Science, vol. 55, no. 19, pp. 4079-4099, 2000.

[4] A. T. Harris, J. F. Davidson, and R. B. Thorpe, "The influence of the riser exit on the particle residence time distribution in a circulating fluidised bed riser," Chemical Engineering Science, vol. 58, no. 16, pp. 3669-3680, 2003.

[5] C. W. Chan, A. Brems, S. Mahmoudi et al., "PEPT study of particle motion for different riser exit geometries," Particuology, vol. 8, no. 6, pp. 623-630, 2010.

[6] X. Wang, L. Liao, B. Fan et al., "Experimental validation of the gas-solid flow in the CFB riser," Fuel Processing Technology, vol. 91, no. 8, pp. 927-933, 2010.

[7] M. T. Lim, S. Pang, and J. Nijdam, "Investigation of solids circulation in a cold model of a circulating fluidized bed," Powder Technology, vol. 226, pp. 57-67, 2012.

[8] J. W. Chew, R. Hays, J. G. Findlay et al., "Reverse core-annular flow of Geldart Group B particles in risers," Powder Technology, vol. 221, pp. 1-12, 2012.

[9] T. Pugsley, D. Lapointe, B. Hirschberg, and J. Werther, "Exit effects in circulating fluidized bed risers," Canadian Journal of Chemical Engineering, vol. 75, no. 6, pp. 1001-1010, 1997.

[10] G. Van engelandt, G. J. Heynderickx, J. De Wilde, and G. B. Marin, "Experimental and computational study of T- and L-outlet effects in dilute riser flow," Chemical Engineering Science, vol. 66, no. 21, pp. 5024-5044, 2011.

[11] J. De Wilde, G. B. Marin, and G. J. Heynderickx, "The effects of abrupt T-outlets in a riser: 3D simulation using the kinetic theory of granular flow," Chemical Engineering Science, vol. 58, no. 3-6, pp. 877-885, 2003.

[12] B. Chalermsinsuwan, P. Kuchonthara, and P. Piumsomboon, "Effect of circulating fluidized bed reactor riser geometries on chemical reaction rates by using CFD simulations," Chemical Engineering and Processing, vol. 48, no. 1, pp. 165-177, 2009.

[13] A. K. Das, J. De Wilde, G. J. Heynderickx, and G. B. Marin, "CFD simulation of dilute phase gas-solid riser reactorspart II: simultaneous adsorption of $\mathrm{SO}_{2}-\mathrm{NO}_{\mathrm{x}}$ from flue gases," Chemical Engineering Science, vol. 59, no. 1, pp. 187-200, 2004.

[14] H. Ali, S. Rohani, and J. P. Corriou, "Modelling and control of a riser type fluid catalytic cracking (FCC) unit," Chemical Engineering Research and Design, vol. 75, no. 4, pp. 401-412, 1997.

[15] I. S. Han and C. B. Chung, "Dynamic modeling and simulation of a fluidized catalytic cracking process-part I: process modeling," Chemical Engineering Science, vol. 56, no. 5, pp. 1951-1971, 2001.

[16] I. S. Han and C. B. Chung, "Dynamic modeling and simulation of a fluidized catalytic cracking process-part II: property estimation and simulation," Chemical Engineering Science, vol. 56, no. 5, pp. 1973-1990, 2001.

[17] S. V. Nayak, S. L. Joshi, and V. V. Ranade, "Modeling of vaporization and cracking of liquid oil injected in a gas-solid riser," Chemical Engineering Science, vol. 60, no. 22, pp. 6049 6066, 2005.
[18] J. S. Ahari, A. Farshi, and K. Forsat, "A mathematical modeling of the riser reactor in industrial FCC unit," Petroleum and Coal, vol. 50, no. 2, pp. 15-24, 2008.

[19] F. Van Landeghem, D. Nevicato, I. Pitault et al., "Fluid catalytic cracking: modelling of an industrial riser," Applied Catalysis A, vol. 138, no. 2, pp. 381-405, 1996.

[20] C. Derouin, D. Nevicato, M. Forissier, G. Wild, and J. R. Bernard, "Hydrodynamics of riser units and their impact on FCC operation," Industrial and Engineering Chemistry Research, vol. 36, no. 11, pp. 4504-4515, 1997.

[21] R. Deng, F. Wei, T. Liu, and Y. Jin, "Radial behavior in riser and downer during the FCC process," Chemical Engineering and Processing, vol. 41, no. 3, pp. 259-266, 2002.

[22] G. C. Lopes, L. M. Rosa, M. Mori, J. R. Nunhez, and W. P. Martignoni, "Three-dimensional modeling of fluid catalytic cracking industrial riser flow and reactions," Computers and Chemical Engineering, 2011.

[23] K. N. Theologos and N. C. Markatos, "Advanced modeling of fluid catalytic cracking riser-type reactors," AIChE Journal, vol. 39, no. 6, pp. 1007-1017, 1993.

[24] K. N. Theologos, A. I. Lygeros, and N. C. Markatos, "Feedstock atomization effects on FCC riser reactors selectivity," Chemical Engineering Science, vol. 54, no. 22, pp. 5617-5625, 1999.

[25] A. Gupta and D. S. Rao, "Model for the performance of a fluid catalytic cracking (FCC) riser reactor: effect of feed atomization," Chemical Engineering Science, vol. 56, no. 15, pp. 4489-4503, 2001.

[26] G. C. Lopes, L. M. Da Rosa, M. Mori, J. R. Nunhez, and W. P. Martignoni, "The importance of using three-phase 3D model in the simulation of industrial FCC risers," Chemical Engineering Transactions, vol. 24, pp. 1417-1422, 2011.

[27] H. Farag, A. Blasetti, and H. De Lasa, "Catalytic cracking with FCCT loaded with tin metal traps: adsorption constants for gas oil, gasoline, and light gases," Industrial and Engineering Chemistry Research, vol. 33, no. 12, pp. 3131-3140, 1994.

[28] S. B. Schut, E. H. Van Der Meer, J. F. Davidson, and R. B. Thorpe, "Gas-solids flow in the diffuser of a circulating fluidised bed riser," Powder Technology, vol. 111, no. 1-2, pp. 94-103, 2000.

[29] L. S. Lee, Y. W. Chen, and T. N. Huang, "Four-lump kinetic model for fluid catalytic cracking process," Canadian Journal of Chemical Engineering, vol. 67, no. 4, pp. 615-619, 1989.

[30] J. A. Juárez, F. L. Isunza, E. A. Rodrìguez, and J. C. M. Mayorga, "A strategy for kinetic parameter estimation in the fluid catalytic cracking process," Industrial \& Engineering Chemistry Research, vol. 36, pp. 5170-5174, 1997.

[31] S. A. Morsi and A. J. Alexander, "An investigation of particle trajectories in two-phase flow systems," The Journal of Fluid Mechanics, vol. 55, no. 2, pp. 193-208, 1972.

[32] Ansys Inc. (US), ANSYS FLUENT 12. 0-Theory Guide, Ansys, 2009.

[33] W. Zhang, Y. Tung, and F. Johnsson, "Radial voidage profiles in fast fluidized beds of different diameters," Chemical Engineering Science, vol. 46, no. 12, pp. 3045-3052, 1991.

[34] J. H. Pärssinen and J. X. Zhu, "Particle velocity and flow development in a long and high-flux circulating fluidized bed riser," Chemical Engineering Science, vol. 56, no. 18, pp. 52955303, 2001.

[35] J. C. S. C. Bastos, L. M. Rosa, M. Mori, F. Marini, and W. P. Martignoni, "Modelling and simulation of a gassolids dispersion flow in a high-flux circulating fluidized bed (HFCFB) riser," Catalysis Today, vol. 130, no. 2-4, pp. 462470,2008 . 
[36] K. N. Theologos, I. D. Nikou, A. I. Lygeros, and N. C. Markatos, "Simulation and design of fluid-catalytic cracking riser-type reactors," Computers and Chemical Engineering, vol. 20, no. 1, pp. S757-S762, 1996.

[37] J. Gao, C. Xu, S. Lin, G. Yang, and Y. Guo, "Simulations of gasliquid-solid 3-phase flow and reaction in FCC riser reactors," AIChE Journal, vol. 47, no. 3, pp. 677-692, 2001.

[38] W. Martignoni and H. I. De Lasa, "Heterogeneous reaction model for FCC riser units," Chemical Engineering Science, vol. 56, no. 2, pp. 605-612, 2001.

[39] J. M. Han and D. L. Liu, "Evaluation on commercial application of LPC type nozzle for FCC feed," Process Engineering Resources, vol. 22, article 49, 1992.

[40] A. T. Harris, J. F. Davidson, and R. B. Thorpe, "Influence of exit geometry in circulating fluidized-bed risers," AIChE Journal, vol. 49, no. 1, pp. 52-64, 2003.

[41] M. P. Martin, P. Turlier, J. R. Bernard, and G. Wild, "Gas and solid behavior in cracking circulating fluidized beds," Powder Technology, vol. 70, no. 3, pp. 249-258, 1992.

[42] X. Wu, F. Jiang, X. Xu, and Y. Xiao, "CFD simulation of smooth and T-abrupt exits in circulating fluidized bed risers," Particuology, vol. 8, no. 4, pp. 343-350, 2010.

[43] M. Liu and J. N. Tilton, "Spatial distributions of mean age and higher moments in steady continuous flows," AIChE Journal, vol. 56, no. 10, pp. 2561-2572, 2010.

[44] F. Wang, Q. Marashdeh, A. Wang, and L. Fan, "Electrical capacitance volume tomography imaging of threedimensional flow structures and solids concentration distributions in a riser and a bend of a gas-solid circulating fluidized bed," Industrial \& Engineering Chemistry Research, vol. 51, pp. 10968-10976, 2012. 

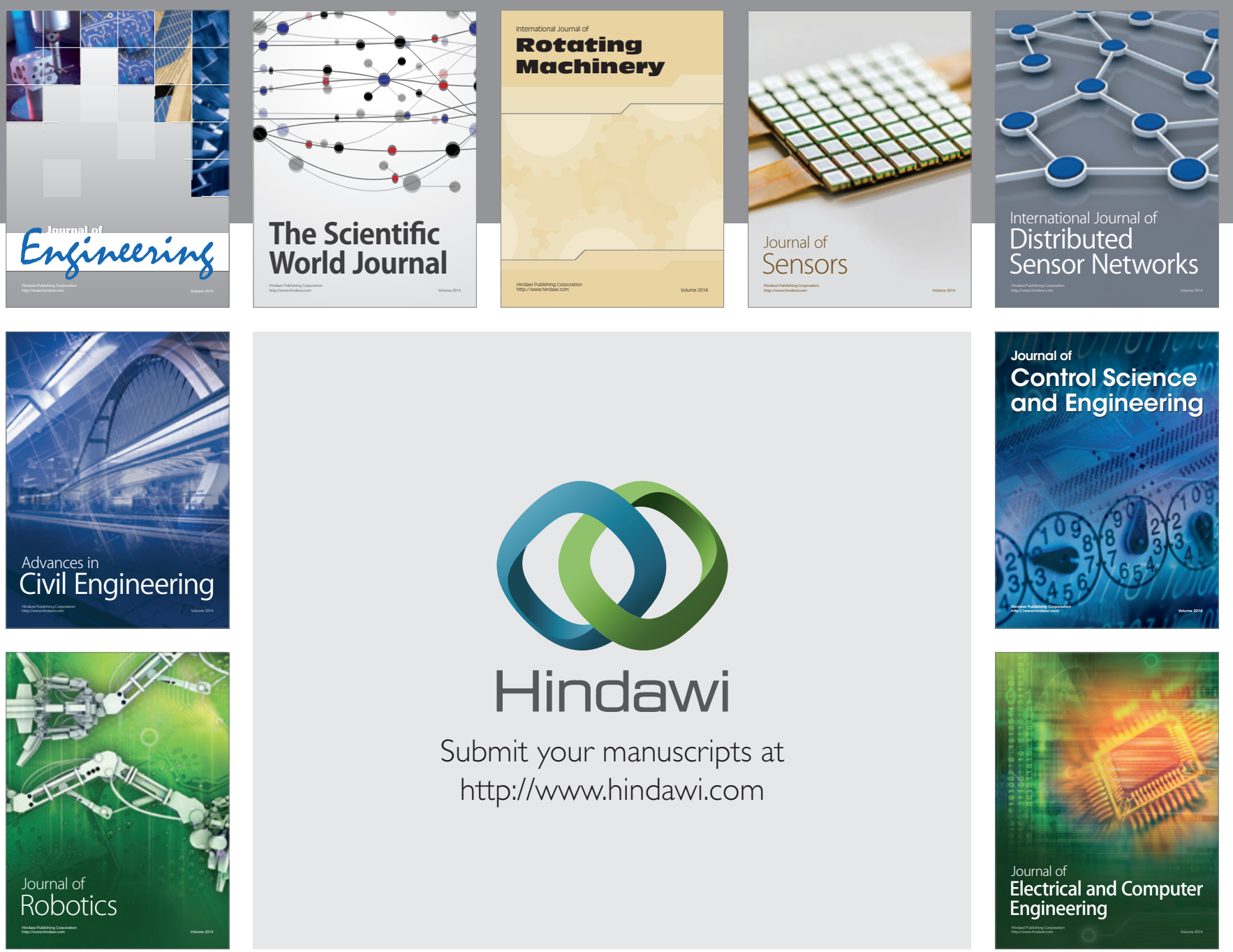

Submit your manuscripts at

http://www.hindawi.com
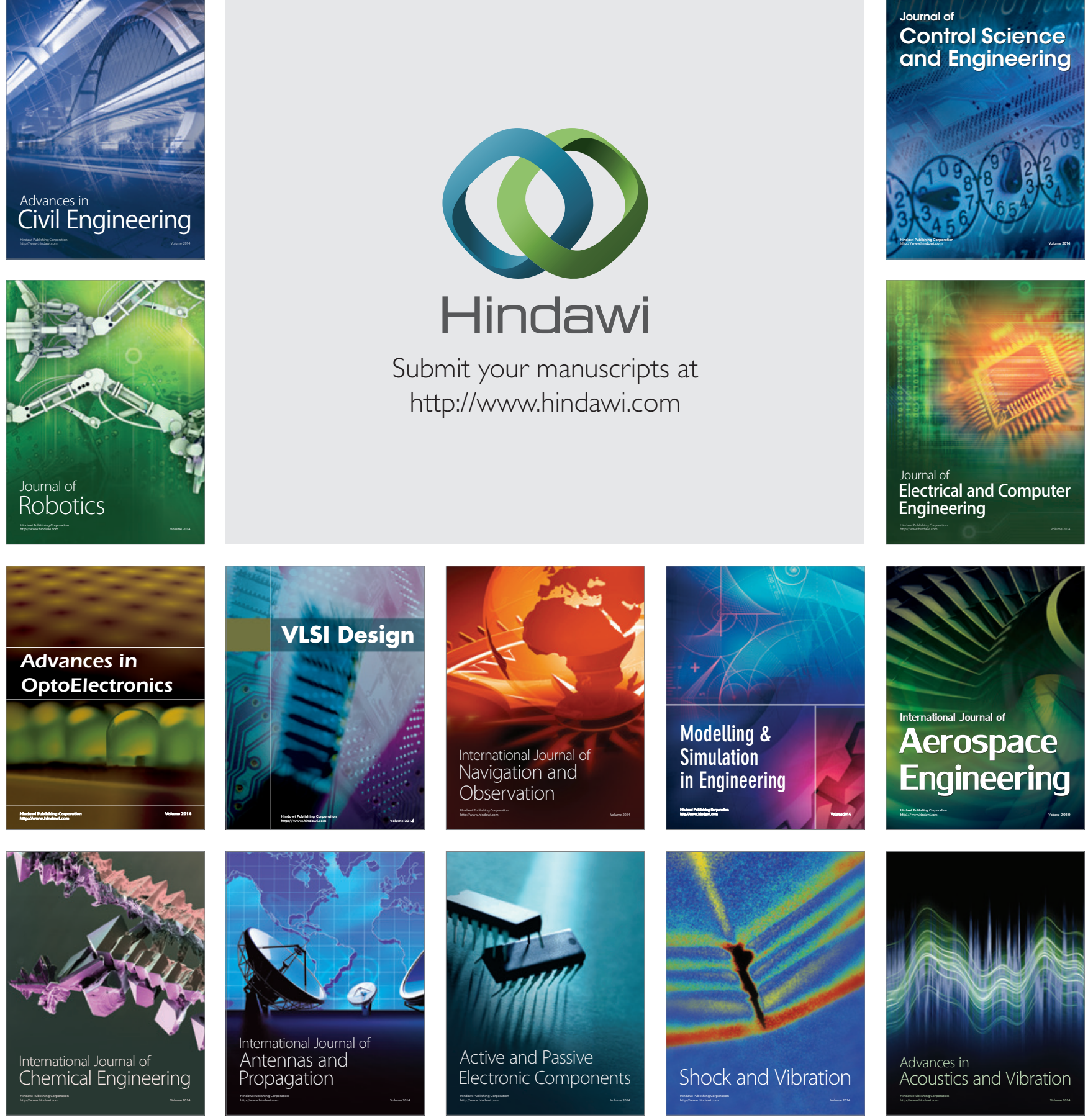